\title{
Role of diatoms in regulating the ocean's silicon cycle
}

\author{
Andrew Yool and Toby Tyrrell \\ Southampton Oceanography Centre, Southampton, UK \\ Received 2 December 2002; revised 16 June 2003; accepted 7 August 2003; published 12 November 2003.
}

[1] Among phytoplankton the diatoms are strong competitors and contribute significantly to total global primary production. Aspects of their life history, notably their high sinking rates, make them important to the export flux of carbon into the ocean interior. Unlike the majority of other phytoplankton, they utilize silicic acid (=silicate) to construct their cell walls and are controlled by its availability and distribution. Here a simple model is developed to study the relationship between the diatoms and the ocean's silicon cycle. The ecological component of this model pits the slightly superior diatoms against all other algae, with both groups competing for phosphate while the diatoms additionally require silicic acid. The model agrees reasonably with observed distributions of nutrients and with their biogeochemical fluxes. While theoretically superior, the diatoms are held in check by the availability of silicic acid, allowing the persistence and numerical dominance of the other algae. The concentrations of both nutrients are homeostatically controlled by the phytoplankton, and resist perturbations. Analysis finds that primary production in the model is ultimately controlled by phosphate, with silicic acid abundance controlling the fraction of the total produced by diatoms. Sensitivity analyses using more ecologically detailed variants of the model find that these results are generally robust. The model's treatment of the "silica pump" hypothesis [Dugdale and Wilkerson, 1998] is also examined. INDEX TERMS: 4805 Oceanography: Biological and Chemical: Biogeochemical cycles (1615); 4815 Oceanography: Biological and Chemical: Ecosystems, structure and dynamics; 4842 Oceanography: Biological and Chemical: Modeling; 4845 Oceanography: Biological and Chemical: Nutrients and nutrient cycling; KEYWORDS: diatoms, silicic acid, ecosystem model, competition, homeostasis

Citation: Yool, A., and T. Tyrrell, Role of diatoms in regulating the ocean's silicon cycle, Global Biogeochem. Cycles, 17(4), 1103, doi:10.1029/2002GB002018, 2003.

\section{Introduction}

[2] In a recent modeling study of the relative roles of nitrogen and phosphorus in controlling phytoplankton abundance, Tyrrell [1999] found that competition between algal groups that differed in their source of nitrogen for metabolism $\left(\mathrm{NO}_{3}\right.$ users versus $\mathrm{N}_{2}$ fixers) was able to produce a "thermostat-like" effect which controlled the level of nitrogen in the surface ocean. The competitive interaction centered on balancing the energetic disadvantage of having to fix nitrogen, with the advantage of being able to do so when ambient nitrate levels were low. This model was able to explain the near-to-origin intercept of nitrate versus phosphate scatterplots and provided insight into competing views about which of these two nutrients most limits phytoplankton production in the ocean.

[3] Figure 1 shows a scatterplot of nitrate versus phosphate, together with a comparable scatterplot of silicic acid versus phosphate. This latter plot also intercepts close to the origin, suggesting that silicic acid may be similarly controlled by the activity of competing algal groups. In

Copyright 2003 by the American Geophysical Union. 0886-6236/03/2002GB002018\$12.00 the contemporary ocean the biogeochemical cycle of silicon is dominated by the activity of the diatoms (class Bacillariophyceae) [Tréguer et al., 1995]. This group is estimated to contribute up to $45 \%$ of total oceanic primary production [Mann, 1999], making them major players in the cycling of all biological elements. Their primary use for silicic acid is in the construction of their cell walls (also known as frustules). This contrasts with other algae that construct their cell coverings from organic material (e.g., cyanobacteria, dinoflagellates) or from calcium carbonate (e.g., coccolithophorids). Tréguer et al. [1995] estimate that globally the diatoms uptake and process 240 Tmol Si $\mathrm{yr}^{-1}$.

[4] In the case of ecological interactions controlling the silicon cycle, the competition may revolve around balancing the burden of a dependence on silicic acid against the competitive advantage of using silicic acid to produce "cheaper" cell walls instead of constructing more energetically "expensive" organic cell walls. On a molar basis, incorporation of silicic acid into a cell wall is calculated to require only $8 \%$ of the energy required for organic carbon [Raven, 1983]. In addition to this potential energetic advantage, several other facets of diatom physiology are believed to give them an ecological advantage over their phytoplank- 

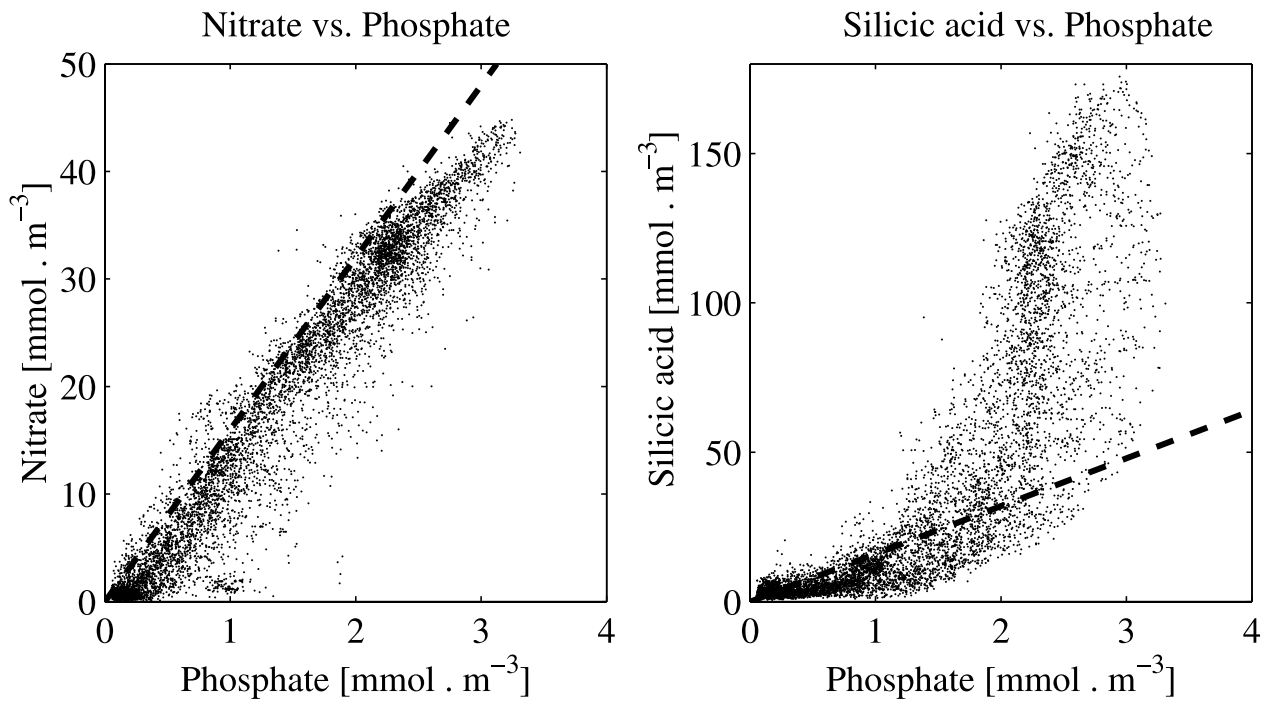

Figure 1. Plots of nitrate versus phosphate and silicic acid versus phosphate from global climatologies [Conkright et al., 1994]. Data range from the surface (near the origin) to the seafloor. The dashed lines represent $\mathrm{N}: \mathrm{P}=16: 1$ and $\mathrm{Si}: \mathrm{P}=16: 1$, standard Redfield ratios for these nutrients. While active remineralization processes closely tie nitrate and phosphate concentrations (even at depth), biogenic silica dissolution is slower and only weakly coupled to these processes; hence the increasing deviation from the dashed line with depth.

ton competitors. Unlike many other algae, whose division cycles are strongly coupled to the diel light cycle, diatoms are capable of dividing at any point of the diel cycle [Martin-Jézéquel et al., 2000]. This light independence extends to their nutrient requirements, with nitrate and silicic acid uptake and storage continuing during the night through the use of excess organic carbon synthesized during the day [Villareal et al., 1999; Martin-Jézéquel et al., 2000; Clark et al., 2002]. It has even been suggested that the presence of biogenic silica acts as an effective $\mathrm{pH}$ buffer, facilitating the conversion of bicarbonate to dissolved $\mathrm{CO}_{2}$ and enabling more efficient photosynthesis [Milligan and Morel, 2002]. These features of diatom physiology almost certainly contribute to the in situ observation that diatoms have greater maximum growth rates relative to comparable algae [Furnas, 1990]. Further, so long as silicic acid is abundant (and other nutrients nonlimiting), diatoms are found to dominate algal communities [Egge and Aksnes, 1992] (but see Egge [1998] for exceptions).

[5] Aside from their role in the silicon cycle, the diatoms have also attracted attention because of their importance to the export of primary production to the ocean's interior. Aggregation and sinking is an important aspect in the life history of many diatom species [Smetacek, 1985], and high sinking velocities, whether as individuals, aggregates or mats, allow diatoms to rapidly transport material out of the surface mixed layer. Additionally, mesozooplankton grazers which consume diatoms produce large, fast-sinking faecal pellets. These processes remove nutrients and carbon from the productive surface waters before they can be remineralized, making the diatoms crucial to "new" (or export) production. From studies of diatoms in the equatorial Pacific Ocean, Dugdale and Wilkerson [1998] have suggested that a "silica pump" controls export to the deep ocean. So long as silicic acid is available, diatoms act as a conduit for nutrients and carbon to deep waters, contrasting with the production of other algae which "traps" nutrients in a regeneration loop at the surface.

[6] Given these features of diatom ecology, two key questions are (1) do switches from siliceous phytoplankton to non-siliceous phytoplankton at low ambient silicic acid provide a critical feedback which controls the ocean's silicic acid content, and (2) if these switches exist, how do they affect ocean productivity and the export flux? The aim of this study is to address these questions by constructing a first-order ecological/biogeochemical model analogous to that of Tyrrell [1999] but which incorporates the silicon cycle and diatoms.

\section{Model Description}

\subsection{Framework}

[7] The model described here follows Tyrrell's [1999] basic framework of simple representations for both the ocean and its ecosystem. By stripping away much of the complexity of real ecosystems, Tyrrell [1999] was able to focus on, and improve understanding of, the key processes in the regulation of nitrate and phosphate in the ocean. This model attempts to do the same for the silicon cycle.

[8] Although the construction of this simple model requires many simplifications and assumptions, our experience with sensitivity analyses shows the model to be relatively insensitive to details of its construction, as will be described in section 4. For example, the micronutrient iron is known to play a significant role in regulating primary production and affecting silicon utilization in diatoms 
[Martin and Fitzwater, 1988; Hutchins and Bruland, 1998]. Although this role is ignored in the base model described in this section, variants of the model involving both implicit and semi-explicit treatments of iron biogeochemistry have been constructed and their significance explored. By building up the ecological/biogeochemical complexity of a firstorder model, the intention is, in part, to determine the operational importance of second-order facets of the silicon cycle.

\subsubsection{Physical Model}

[9] The ocean is represented by a standard one-dimensional, two-box model [Broecker, 1971]. The two boxes resolve the ocean vertically into a surface layer (0 to $500 \mathrm{~m})$ and a deep layer (500 to $3720 \mathrm{~m}$ ). A constant amount of mixing between these two layers is parameterized to represent ocean overturning, upwelling and diffusion.

\subsubsection{Biogeochemical Model}

[10] The ocean's biogeochemistry is reduced to only two nutrients and two phytoplankton groups. Both nutrients are present in both ocean boxes, but the phytoplankton groups are confined to the surface box (which represents the seasonally mixed zone down to the permanent thermocline). Figure 2 shows a diagrammatic overview of the model biogeochemistry. Although it would be more accurate to include a separate representation of the euphotic zone (e.g., the top $100 \mathrm{~m}$ ), sensitivity analysis (see section 4.2) finds that this is less important than might be supposed.

[11] The nutrients included in the model are phosphate and silicic acid. Because of its important role in genetic and metabolic machinery, phosphate is required by all algae, but silicic acid is only a major requirement of siliceous algae. Both nutrients are supplied to the ocean by rivers, and silicic acid has additional inputs from aeolian, hydrothermal and seafloor weathering sources. Both are consumed by algae in the model's surface layer and remineralized down the water column when the algae die and sink into the ocean. The rates at which the two nutrients are remineralized are different (phosphate remineralizes faster, and therefore higher in the water column, than silicic acid), and this is reflected in the model by different partitioning of remineralization between the two ocean boxes. Small fractions of the sinking fluxes of both nutrients are lost permanently from the model system through the sedimentation and burial of biogenic material on the seafloor. Again, the two nutrients differ in the fraction of sinking material that is ultimately buried and lost from the model.

[12] The two phytoplankton groups modeled are the diatoms and other algae. More generally these represent siliceous algae and non-siliceous algae. The diatoms require both silicic acid and phosphate to grow, and uptake these nutrients in a variable ratio [Martin-Jézéquel et al., 2000]. Their growth rate is controlled by the most limiting of the two nutrients in a Liebig's Law formulation. The growth rate of the other algae is controlled solely by the availability of phosphate. While only diatoms are modeled here, other groups, notably the sponges and radiolarians, also utilize silicic acid. However, although these groups have been important in the silicon cycle of earlier Eras [Siever, 1991; Kidder and Erwin, 2001], they play relatively minor roles in the contemporary ocean [Tréguer et al., 1995].
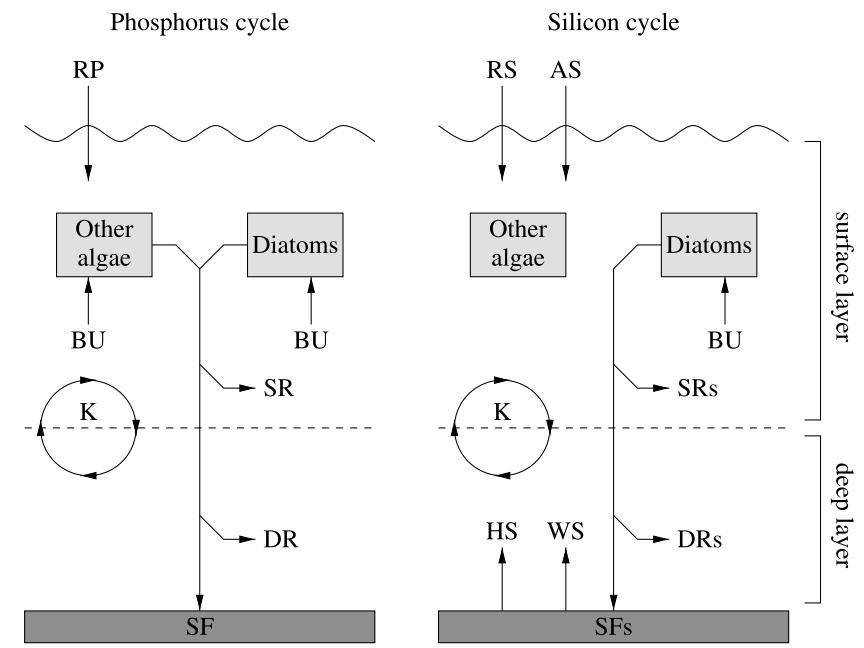

Figure 2. Structure of the model's two nutrient cycles. The ocean's biogeochemistry is reduced to two nutrients (phosphate and silicic acid; surface and deep boxes) and two competing phytoplankton groups (diatoms and other algae; surface box only). RP, riverine phosphate; RS, riverine silicic acid; AS, aeolian silicic acid; HS, hydrothermal silicic acid; WS, seafloor weathering silicic acid; BU, biological uptake; SR, surface phosphate remineralization; DR, deep phosphate remineralization; SF, phosphate sedimentation; SRs, surface silica dissolution; DRs, deep silica dissolution; SFs, silica sedimentation; K, ocean mixing. Note that deep remineralization of phosphate (DR) and dissolution of silica (DRs) occur both down the water column and at the sediment-water interface on the seafloor.

[13] Within the bounds imposed by their differing nutrient requirements, both algal groups are modeled and parameterized in the same way. Both use the same MichaelisMenten uptake curve for phosphate, and both algae are assumed to die at the same rate. However, the maximum growth rates of the two algal groups are not equal. As diatoms are generally found to be superior competitors wherever silicic acid is not limiting, or is less limiting than other macronutrients [Furnas, 1990; Egge and Aksnes, 1992], their maximum growth rate is set at a value fractionally greater than that of the other algae to give them a competitive edge. This approach aims to simplify the ecological model to the assertions that (1) all other things being equal, diatoms are superior competitors and (2) only diatoms require (and are potentially limited by) silicic acid. Other differences between diatoms and the other algae (e.g., photosynthesis/nutrient coefficients, respiration/mortality/ sinking rates, etc.) are, for the purposes of clarity, ignored. The sensitivity of the model to these assumptions is explored in detail later.

\subsection{Equations}

[14] The model has six state variables corresponding to diatoms, $D$, other algae, $O$, surface phosphate, $P_{s}$, surface silicic acid, $S_{s}$, deep phosphate, $P_{d}$, and deep silicic acid, $S_{d}$. Since it is the sole common currency, both phytoplank- 
ton equations are written in terms of phosphate. Units are $\mathrm{mol} \mathrm{m}^{-3}$.

$$
\begin{aligned}
& \frac{d O}{d t}=+\underbrace{\left[\mu_{O} \cdot \frac{P_{s}}{P_{s}+K_{p}} \cdot O\right]}_{\text {growth }}-\underbrace{[M \cdot O]}_{\text {mortality }}, \\
& \frac{d D}{d t}=+\underbrace{\left[\mu_{D} \cdot \min \left(\frac{P_{s}}{P_{s}+K_{p}}, \frac{S_{s}}{S_{s}+K_{s}}\right) \cdot D\right]}_{\text {growth }}-\underbrace{[M \cdot D]}_{\text {mortality }}, \\
& \frac{d P_{s}}{d t}=-\underbrace{\left[\mu_{O} \cdot \frac{P_{s}}{P_{s}+K_{p}} \cdot O\right]}_{\text {O uptake }}-\underbrace{\left[\mu_{D} \cdot \min \left(\frac{P_{s}}{P_{s}+K_{p}}, \frac{S_{s}}{S_{s}+K_{s}}\right) \cdot D\right]}_{\text {D uptake }} \\
& +\underbrace{[S R \cdot M \cdot O]}_{\text {O surface P remin }}+\underbrace{[S R \cdot M \cdot D]}_{\text {D surface P remin }}+\underbrace{\left[K \cdot \frac{P_{d}-P_{s}}{S D}\right]}_{\text {ocean mixing }}+\underbrace{\left[\frac{R P}{S D}\right]}_{\text {riverine input }} \text {, }
\end{aligned}
$$

$$
\begin{aligned}
\frac{d S_{s}}{d t}= & -\underbrace{\left[\mu_{D} \cdot \min \left(\frac{P_{s}}{P_{s}+K_{p}}, \frac{S_{S}}{S_{s}+K_{s}}\right) \cdot D \cdot \hat{R}_{\text {org }}\right]}_{\text {D uptake }} \\
& +\underbrace{\left[S R_{S} \cdot M \cdot D \cdot \hat{R}_{\text {org }}\right]}_{\text {D surface Si remin }}+\underbrace{\left[K \cdot \frac{S_{d}-S_{s}}{S D}\right]}_{\text {ocean mixing }}+\underbrace{\left[\frac{R S+A S}{S D}\right]}_{\text {riverine and aeolian input }},
\end{aligned}
$$

$$
\frac{d P_{d}}{d t}=+\underbrace{\left[D R \cdot M \cdot O \cdot \frac{S D}{D D}\right]}_{\text {O deep P remin }}+\underbrace{\left[D R \cdot M \cdot D \cdot \frac{S D}{D D}\right]}_{\text {D deep P remin }}-\underbrace{\left[K \cdot \frac{\left.P_{d}-P_{S}\right]}{D D}\right]}_{\text {ocean mixing }},
$$

$$
\begin{aligned}
\frac{d S_{d}}{d t}= & +\underbrace{\left[D R_{s} \cdot M \cdot D \cdot \hat{R}_{\text {org }} \cdot \frac{S D}{D D}\right]}_{\text {D deep Si remin }}-\underbrace{\left[K \cdot \frac{S_{d}-S_{S}}{D D}\right]}_{\text {ocean mixing }} \\
& +\underbrace{\left[\frac{H S+W S}{D D}\right]}_{\text {hydrothermal and weathering input }},
\end{aligned}
$$

where,

$$
\hat{R}_{\text {org }}=R_{\text {org }} \cdot\left[\frac{S_{s}}{S_{s}+K_{s}}\right] \cdot\left[\min \left(\frac{P_{s}}{P_{s}+K_{p}}, \frac{S_{s}}{S_{s}+K_{s}}\right)\right]^{-1}
$$

[15] Both phytoplankton equations are composed of two terms. The first is a simple growth term, relating population increase to the current population, a maximum growth rate $\left(\mu_{O}\right.$ or $\left.\mu_{D}\right)$, and a standard Michaelis-Menten term for nutrient uptake. In the diatom equation, the lower of the two nutrient limitation terms controls the rate of population increase through a Liebig's Law formulation. Although seemingly considerably simpler, these growth terms differ from those of other plankton models [e.g., Fasham, 1993] mainly in the reduction of the light-limited portion of the growth rate to a single parameter. This simplification is permitted because the model aims to represent the global nutrient cycles on a mean annual basis. Should the model be used in a seasonal context, the growth terms would need to be specified in greater detail.

[16] The second term in the phytoplankton equations is a loss rate, removing a constant fraction $(M)$ of the phytoplankton populations. This term simplifies all of the possible loss pathways for phytoplankton (e.g., grazing, respiration, sinking, disease) down to a single, linear rate. It is considerably simpler than corresponding terms in other plankton models. Commonly, loss terms are represented by explicitly modeling zooplankton populations, which act to graze down phytoplankton populations. These grazing relationships are usually modeled in a nonlinear fashion similar to that of nutrient uptake, and are often further complicated by parameterizing multiple prey types, grazing thresholds, or food preferences [Fasham et al., 1990]. The simplification used here keeps the model analytically tractable and concentrates on the most important processes (but see section 4.2 for relevant sensitivity analyses).

[17] Phytoplankton growth and loss terms dominate the fluxes for both modeled nutrients. Growth reduces surface concentrations of nutrients, while phytoplankton losses are returned to both ocean boxes by the remineralization of sinking biogenic material. Remineralization is modeled as the fractions of the sinking flux of biogenic material that are remineralized within each ocean layer. In reality, these fractions vary with detrital sinking speed and with remineralization rate, which themselves vary with aggregation/ breakup of particles, and with ambient temperature, pressure, and oxygen concentration. Rather than address this complexity directly, simple remineralization fractions have been assumed for both nutrients. Further, as a preliminary assumption, remineralization of detrital phosphate from both algal groups is parameterized identically. This assumption ignores the role of sinking in diatom ecology [Smetacek, 1985; Dugdale and Wilkerson, 1998], according to which one would expect the remineralization profile of diatomproduced biogenic phosphate to be shifted towards the deep box. This assumption is examined in section 5 .

[18] Unlike the ratios between the other major elements, the ratio between silicon and phosphorus (or carbon or nitrogen) can be extremely variable in diatoms. First, silicic acid uptake, unlike that of nitrate and phosphate, is decoupled from photosynthesis, although it is still ultimately dependent on the energy provided by photosynthesis [Martin-Jézéquel et al., 2000]. Further, silicification is tightly coupled to the cell division cycle, resulting in the extent of silicification being dependent on the duration of the division cycle [Ragueneau et al., 2000; Martin-Jézéquel et al., 2000]. The slower a cell grows, the longer a period it has to uptake silicic acid, and so the more heavily silicified it becomes (assuming silicic acid is abundant relative to other limiting factors). For example, the availability of iron, known to be regionally variable, is widely believed to play a 
Table 1. Model Parameters and Their Values

\begin{tabular}{|c|c|c|c|c|}
\hline \multirow{2}{*}{$\frac{\text { Symbol }}{S D}$} & Parameter & \multirow[t]{2}{*}{ Value } & \multicolumn{2}{|c|}{ Literature } \\
\hline & depth of surface layer & & & \\
\hline$D D$ & depth of deep layer & $3230 \mathrm{~m}$ & & \\
\hline Tvol & total ocean volume & $135 \times 10^{16} \mathrm{~m}^{3}$ & & \\
\hline Tarea & total ocean surface area & $362 \times 10^{12} \mathrm{~m}^{2}$ & & \\
\hline$K$ & ocean mixing coefficient & $3.0 \mathrm{~m} \mathrm{yr}^{-1}$ & 3.0 & [Broecker and Peng, 1982] \\
\hline$S R$ & fraction of $\mathrm{P}$ remineralized in surface & $95 \%$ & $92-97$ & [Tyrrell, 1999] \\
\hline$D R$ & fraction of $\mathrm{P}$ remineralized in deep & $4.8 \%$ & $(100-S R-S F)$ & \\
\hline$S F$ & sedimentation fraction of $\mathrm{P}$ & $0.2 \%$ & $0.1-0.2$ & [Mackenzie et al., 1993] \\
\hline$S R_{S}$ & fraction of $\mathrm{Si}$ dissolution in surface & $50 \%$ & 50 & [Tréguer et al., 1995] \\
\hline$D R_{s}$ & fraction of Si dissolution in deep & $47.5 \%$ & $\left(100-S R_{s}-S F_{S}\right)$ & \\
\hline$S F_{s}$ & sedimentation fraction of $\mathrm{Si}$ & $2.5 \%$ & 2.5 & [Tréguer et al., 1995] \\
\hline$R P$ & riverine $\mathrm{P}$ input & $0.2 \mathrm{mmol} \mathrm{P} \mathrm{m}^{-2} \cdot \mathrm{yr}^{-1}$ & $0.09-0.21$ & [Tyrrell, 1999] \\
\hline$R A S$ & riverine $\mathrm{Si}$ input & $15.0 \mathrm{mmol} \mathrm{Si} \mathrm{m}{ }^{-2} \cdot \mathrm{yr}^{-1}$ & $13.8 \pm 2.7$ & [Tréguer et al., 1995] \\
\hline$A S$ & aeolian $\mathrm{Si}$ input & $1.5 \mathrm{mmol} \mathrm{Si} \mathrm{m} \mathrm{m}^{-2} \cdot \mathrm{yr}^{-1}$ & $1.4 \pm 1.4$ & [Tréguer et al., 1995] \\
\hline$H S$ & hydrothermal Si input & $0.6 \mathrm{mmol} \mathrm{Si} \mathrm{m}{ }^{-2} \cdot \mathrm{yr}^{-1}$ & $0.4 \pm 0.3$ & [Tréguer et al., 1995] \\
\hline$W S$ & weathering Si input & $1.2 \mathrm{mmol} \mathrm{Si} \mathrm{m}{ }^{-2} \cdot \mathrm{yr}^{-1}$ & $1.1 \pm 0.8$ & [Tréguer et al., 1995] \\
\hline$R_{\text {org }}$ & minimum Si:P ratio in organic matter & $16 \mathrm{~mol} \mathrm{Si}(\mathrm{mol} \mathrm{P})^{-1}$ & 16 & [Louanchi and Najjar, 2000] \\
\hline$\mu_{O}$ & maximum $\mathrm{O}$ growth rate & $91.25 \mathrm{yr}^{-1}\left(=0.25 \mathrm{~d}^{-1}\right)$ & $36-1500$ & [Furnas, 1990] \\
\hline$\mu_{D}$ & maximum $\mathrm{D}$ growth rate & $94.9 \mathrm{yr}^{-1}\left(=0.26 \mathrm{~d}^{-1}\right)$ & $36-1500$ & [Furnas, 1990] \\
\hline$K_{p}$ & $\mathrm{P}$ uptake half-saturation constant & $0.03 \mathrm{mmol} \mathrm{P} \mathrm{m}^{-3}$ & $0.03-0.05$ & {$[$ Tyrrell, 1999] } \\
\hline$\stackrel{p}{K_{s}}$ & Si uptake half-saturation constant & $0.5 \mathrm{mmol} \mathrm{Si} \mathrm{m}^{-3}$ & $0.2-97.4$ & [Martin-Jézéquel et al., 2000] \\
\hline$M$ & mortality rate & $73.0 \mathrm{yr}^{-1}\left(=0.20 \mathrm{~d}^{-1}\right)$ & $91-440$ & [Banse, 1992] \\
\hline
\end{tabular}

role in the silicic acid utilization in diatoms via its effects on cell growth rates [Hutchins and Bruland, 1998; Takeda, 1998], with the result that higher Si:P ratios are found within diatoms growing in iron-limited regions [Pondaven et al., 1998].

[19] In the equations above, this general relationship is modeled by relating the $\mathrm{Si}: \mathrm{P}$ ratio, $\hat{R}_{\text {org }}$, to a function of the silicic acid uptake rate and the Liebig term. Thus, when silicic acid most limits the diatoms, the numerator and denominator in the $\hat{R}_{\text {org }}$ equation are equal and a $\mathrm{Si}: \mathrm{P}$ ratio of $R_{\text {org }}$ results (this is assumed to be the minimum $\mathrm{Si}: \mathrm{P}$ ratio). However, where silicic acid is more plentiful and phosphate most limits the diatoms (i.e., extends the duration of the cell division cycle), the numerator is greater than the denominator and $\hat{R}_{\text {org }}>R_{\text {org }}$. The minimum ratio used here should be viewed as the diatoms' ideal ratio: When conditions are good, and both nutrients are nonlimiting, this is the ratio that will result within actively growing diatom populations. When under severe silicic acid stress [Martin-Jézéquel et al., 2000], diatoms may curtail frustule size (either via reduced thickness or ornamentations such as spines) to lower their silicic acid requirement and so reduce their Si:P ratio. Although the model does not represent this response, the conditions that lead to it are only likely to occur at times and places when diatoms are less ecologically important, so we have not included this response. Essentially, while the relationship used here simplifies a complex process [Flynn and Martin-Jézéquel, 2000], it captures a major facet of the $\mathrm{Si}: \mathrm{P}$ ratio and, from a practical point of view, requires no extra parameters beyond the ideal Si:P ratio.

[20] Aside from the biologically controlled fluxes, both nutrients are constantly added to the ocean from terrestrial or seafloor reservoirs. In the case of phosphate, these are confined to riverine fluxes entering the surface layer $(R P)$. Riverine fluxes dominate silicic acid additions to the ocean [Tréguer et al., 1995], but these are supplemented by aeolian inputs (also to the surface layer), and hydrothermal and seafloor weathering inputs which enter the deep layer of the model (respectively, $R S, A S, H S$, and $W S$ ). Since the representation of ocean physics is primitive, nutrients in the two layers are simply mixed at a constant rate $(K)$ between the two ocean layers.

[21] An important process only implicit in the equations above is the burial and permanent loss of material from the ocean system. As outlined above, sinking biogenic material is remineralized down the water column, with the two layers receiving fractions $\left(S R, D R, S R_{S}\right.$ and $\left.D R_{S}\right)$ of the total biogenic flux. For both nutrients, these fractions sum to less than 1, and residual quantities of material leave the modeled system $\left(S F\right.$ and $S F_{s}$; see Table 1). Given that there are constant inputs from riverine and other sources, and that this burial flux is the only "exit" from the model system, it is an important pathway in determining the ocean's equilibrium state, despite being invisible in the model equations.

\subsection{Parameters}

[22] Table 1 lists all of the model's parameters together with their descriptions, units and values. All material units are expressed in moles, spatial dimensions in meters, and time in years. Remineralization fractions are given as percentages, although in the model they are used as fractions of unity.

[23] The majority of the model parameters are derived from Tyrrell's [1999] model. Both that model and this one share the same phosphate cycle submodels, and the parameters they have in common are given identical values here. One slight difference lies in the values assigned to the phytoplankton maximum growth rates. In the work of Tyrrell [1999] the other algae are given a slight advantage over their nitrogen fixing competitors $\left(0.25 \mathrm{~d}^{-1}\right.$ versus $\left.0.24 \mathrm{~d}^{-1}\right)$, while in this model the diatoms are given a similarly slight advantage over the other algae $\left(0.26 \mathrm{~d}^{-1}\right.$ versus $\left.0.25 \mathrm{~d}^{-1}\right)$. Both algae experience the same mortality rate $\left(M=0.20 \mathrm{~d}^{-1}\right)$.

[24] These maximum growth and death rates are considerably lower than most values obtained from the field and 
cultures. However, as the model is a global annual model, these higher rates have been modified to reflect the growth rates experienced by phytoplankton on this time and space basis. Weighting by time, space, and biomass, Palmer and Totterdell's [2001] globally resolved plankton model finds that the average phytoplankton cell is, before nutrient limitation, growing at around $26 \%$ its maximum growth rate due to the shortage of light in many places at many times.

[25] The parameterization of the silicon cycle submodel is mostly based on the comprehensive review of Tréguer et al. [1995]. This review summarizes the best estimates for the fluxes of silicic acid through the ocean, and constructs a budget for silicon for the global ocean. The values of the parameters dealing with fluxes of silicic acid into the ocean $(R S, A S, H S$, and $W S$ ) are simply taken from this budget.

[26] The pattern of dissolution of biogenic silica down the water column in the model is also taken from the budget. However, this simple appropriation of values does have problems. Surface dissolution in the budget $(50 \%)$ is estimated for the upper $200 \mathrm{~m}$ of the ocean, rather than the $500 \mathrm{~m}$ used in the model. Using an explicit model of the sinking and dissolution of silica down the water column, it should be possible to correct the value of $S R_{S}$ for this thicker surface layer. Kamatani [1982] presents a first-order, temperaturedependent silica dissolution equation calculated from experiments with diatom cultures. Combining this with a temperature profile and constant sinking rate, it is possible to produce curves of silica dissolution with depth. However, using the parameter ranges determined by Kamatani [1982] and a range of sinking velocities, it was not possible to produce a curve which satisfied Tréguer et al.'s [1995] budget. The detailed ecosystem model of Pondaven et al. [1998] also uses Kamatani's [1982] equation in its representation of silica dissolution, but does so with two size classes (and thus sinking velocities) of silica detritus. This approach could be used here to produce a composite dissolution curve from two (or more) other curves which would satisfy the budget. However, Pondaven et al.'s [1998] model is considerably more complicated than the model used here, and its proportioning of biogenic silica into the two different size classes is a dynamic part of the model. As such, it would be difficult to replicate within the framework of a global annual model. To this end, Tréguer et al.'s [1995] dissolution fractions have been used as they are. Section 4.1 explores alternative values of these parameters.

[27] To determine their use of silicic acid, two other diatom parameters need to be specified: silicic acid uptake halfsaturation, $K_{s}$, and minimum silicon to phosphorus uptake ratio, $R_{\text {org. }}$. Not uncommonly for biological variables, both of these parameters have wide ranges in the literature, though both also appear to vary with other properties such as ambient silicic acid or cell division rate. In the case of $K_{s}$, MartinJézéquel et al. [2000] find a range from 0.2 to $97.4 \mathrm{mmol}$ $\mathrm{Si} \mathrm{m}{ }^{-3}$ in a review of culture experiments. Pondaven et al. [1998] report a rectilinear relationship between field measurements of ambient silicic acid and $K_{s}$, with values rising linearly $1: 1$ with silicic acid until concentrations around $40 \mathrm{mmol} \mathrm{Si} \mathrm{m}{ }^{-3}$, after which values of $K_{s}$ plateau (though still with considerable variability). In the first instance, a value for $K_{s}$ at the lower end of the range has been chosen.
[28] Like $K_{s}$, the ratio between phosphate and silicic acid in diatom cells is variable. As discussed previously, the model includes a function intended to replicate a source of this variability (cell cycle duration). This function requires a minimum (or ideal) Si:P ratio, $R_{\text {org }}$. Following Louanchi and Najjar's [2000] global survey of nutrient cycles (as well as for the purposes of simplicity) a minimum Si:N ratio of 1:1 has been chosen, which translates to an $\mathrm{Si}: \mathrm{P}$ ratio of 16:1. This ratio also matches that found by Dugdale and Wilkerson [1998] in their regional study of diatom production in the equatorial Pacific upwelling zone.

\section{Model Results}

\subsection{Analytical Solution}

[29] One approach to determine the importance of individual processes to the behavior of the silicon cycle is to calculate the model's equilibrium, or steady state. Given its equations, the steady state solution for the model can readily be calculated by setting the solutions of the differential equations to 0 . This produces six simultaneous equations in the six state variables which are solved to obtain the analytical solutions. However, there is a complication in the case of this model.

[30] Since the equations contain a minimizing function in the diatom growth term, two potential solutions exist: one in which the diatoms are limited by phosphate, the other in which they are limited by silicic acid. It is possible, and relatively simple, to determine the identity of the most limiting nutrient. Mathematical analysis produces an expression containing only the input and sedimentation parameters for both nutrients, from which it can be shown that the diatoms are limited by silicic acid (given the baseline parameter values).

[31] Making the appropriate substitution into the diatom growth term, the following steady state solutions are obtained:

$$
\begin{gathered}
O^{*}=\frac{1}{M \cdot S D} \cdot\left[\frac{R P}{S F}\right]-D^{*} \\
D^{*}=\frac{1}{M \cdot S D} \cdot\left[\frac{R S+A S+H S+W S}{S F_{s} \cdot R_{o r g}}\right] \\
P_{s}^{*}=\frac{M \cdot K_{p}}{\mu_{O}-M} \\
S_{s}^{*}=\frac{M \cdot K_{s}}{\mu_{D}-M}, \\
S_{d}^{*}=S_{s}^{*}+\frac{1}{K} \cdot\left[\frac{D R_{s} \cdot(R S+A S+H S+W S)}{S F_{s}}+(H S+W S)\right] .
\end{gathered}
$$


[32] In the case of the phytoplankton solutions, both are primarily limited by the rates of supply and loss of their limiting nutrient. In the case of the diatoms, their only consideration (being silicic acid-limited) is in the dynamics of silicic acid. The greater the supply of silicic acid to the ocean, or the smaller the fraction of biogenic silica that sediments out, the greater the standing stock of the diatoms. However, in the case of the other algae, their standing stock is dependent not only on the dynamics of phosphate, but also on the standing stock of the diatom population. Since there is only a fixed amount of phosphate to go around, the more successful the diatoms, the less successful the other algae.

[33] The surface concentrations of both nutrients are entirely independent of nutrient supply rates and phytoplankton standing stocks, but are instead solely dependent on phytoplankton growth and loss parameters. By contrast, deep concentrations of both nutrients are dependent primarily on nutrient supply and sedimentation rates, but also on the fraction of nutrient remineralized in the deep layer, and the rate of mixing between the two ocean boxes. The concentrations of nutrients in the surface layer also enter into these solutions, although because these concentrations are typically low, their contribution is somewhat less important.

[34] Since the diatoms are silicic acid-limited at equilibrium, the variable $\mathrm{Si}: \mathrm{P}$ ratio, $\hat{R}_{\text {org }}$, collapses to the minimum ratio, $R_{\text {org }}$. However, since this is an equilibrium solution, it does not preclude a dynamically varying ratio during simulations far from equilibrium.

[35] Further equations can be derived from those above for various properties of the modeled system:

$$
\begin{aligned}
& \text { Total primary production }=\frac{R P}{S D \cdot S F} \mathrm{mmol} \mathrm{P} \mathrm{m}^{-3} \mathrm{yr}^{-1} \\
& \text { Export across } 500 \mathrm{~m}=\frac{(1-S R)}{S D} \cdot \frac{R P}{S F} \mathrm{mmol} \mathrm{P} \mathrm{m}^{-3} \mathrm{yr}^{-1} \text {, }
\end{aligned}
$$

$$
\begin{aligned}
& \text { Diatom biomass fraction }=\frac{(R S+A S+H S+W S) \cdot S F}{R P \cdot S F_{S} \cdot R_{\text {org }}}, \\
& \mathrm{P} \text { sedimentation }=\frac{R P}{S D} \text { mmol } \mathrm{P} \mathrm{m} \mathrm{m}^{-3} \mathrm{yr}^{-1},
\end{aligned}
$$

Si sedimentation $=\frac{R S+A S+H S+W S}{S D} \mathrm{mmol} \mathrm{Si} \mathrm{m}^{-3} \mathrm{yr}^{-1}$,

$$
\text { Surface Si : P ratio }=\frac{K_{s} \cdot\left(\mu_{O}-M\right)}{K_{p} \cdot\left(\mu_{D}-M\right)} \text { mol Si }(\operatorname{mol~P})^{-1} \text {. }
$$

To facilitate comparison of these properties, the appropriate equations above are scaled with respect to the thickness of the model ocean's surface layer, $S D$. Rates per unit volume refer to volume of this surface layer.
[36] Echoing Tyrrell [1999], total primary production and biogenic export to the deep ocean are controlled here by phosphate supply and removal. The silicon cycle does not affect total production, but merely the fraction of it which is contributed by the diatoms. Biogenic silica production is the reverse of this, being solely controlled by the rate of silicic acid supply to the ocean and its sedimentation fraction. The actual fraction of total phytoplankton biomass that is made up of diatoms is a composite function of the rates of supply and sedimentation of both phosphate and silicic acid.

[37] Note that the steady state determined above only applies over long timescales (ky to My). The analysis ignores the dynamical behavior of the model during its evolution towards this steady state.

\subsection{Numerical Solution}

[38] Substituting the values of the model's parameters into the steady state equations produces the following values for the six state variables and key system properties.

$$
\begin{aligned}
& \mathrm{O}^{*}=1.486 \mu \mathrm{mol} \mathrm{P} \mathrm{m}^{-3} \\
& \mathrm{D}^{*}=1.253 \mu \mathrm{mol} \mathrm{P} \mathrm{m}{ }^{-3} \\
& \mathrm{P}_{\mathrm{s}}^{*}=0.120 \mathrm{mmol} \mathrm{P} \mathrm{m}^{-3} \\
& \mathrm{~S}_{\mathrm{S}}^{*}=1.667 \mathrm{mmol} \mathrm{Si} \mathrm{m}^{-3} \\
& \mathrm{P}_{\mathrm{d}}^{*}=1.720 \mathrm{mmol} \mathrm{P} \mathrm{m}^{-3} \\
& \mathrm{~S}_{\mathrm{d}}^{*}=118.2 \mathrm{mmol} \mathrm{Si} \mathrm{m}^{-3}
\end{aligned}
$$

Total primary production $=36.20 \mathrm{Tmol} \mathrm{P} \mathrm{yr}^{-1}$

Export across $500 \mathrm{~m}=1.180 \mathrm{Tmol} \mathrm{P} \mathrm{yr}^{-1}$

Biogenic Si production $=265.0 \mathrm{Tmol} \mathrm{Si} \mathrm{yr}^{-1}$

Diatom biomass fraction $=45.75 \%$

$\mathrm{P}$ sedimentation $=72.40 \mathrm{Gmol} \mathrm{P} \mathrm{yr}^{-1}$

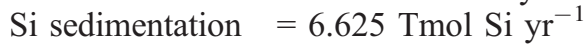

Surface Si: P ratio $=13.89 \mathrm{~mol} \mathrm{Si}(\mathrm{mol} \mathrm{P})^{-1}$.

At the steady state, the diatoms, while more competitive than the other algae, attain a slightly lower fraction of the total biomass. The root of this result lies in the relative supply and removal rates of the two nutrients. Although the supply rate of silicic acid relative to phosphate is high ( $\mathrm{Si}: \mathrm{P}=91.5)$, it is also more efficiently removed through burial. The balance of these two processes makes silicic acid more limiting to diatoms than phosphate (this can be seen in the analytical solution for diatom fraction). Consequently, diatom dominance is held in check by silicic acid abundance, preventing them from consuming more of the phosphate and allowing the other algae "breathing space" to coexist.

[39] Figure 3 summarizes the fluxes in both the phosphorus and silicon budgets at the model equilibrium. Note that the sedimentation fluxes of both nutrients balance the corresponding input fluxes to the ocean. Since phosphate is added solely to the ocean's surface layer, its upwelling flux also balances its deep remineralization flux. In the case of silicic acid, these fluxes are slightly out of balance because of the input of silicic acid at the seafloor.

\subsection{Reality Check}

[40] The steady state solution predicts values for various properties which may be compared with observations of the 


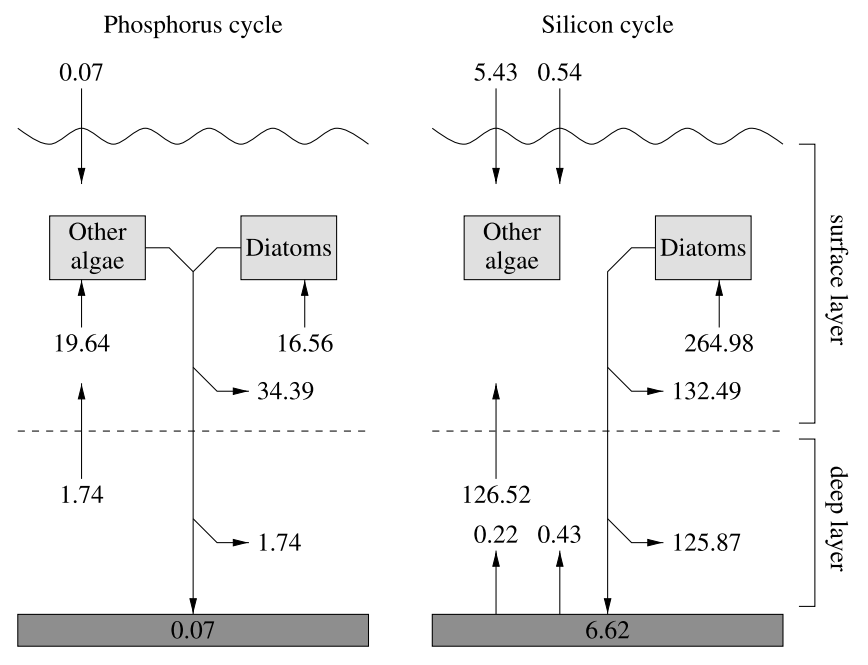

Figure 3. Model equilibrium budgets for the phosphorus and silicon cycles. All fluxes are in Tmol $\mathrm{yr}^{-1}$.

contemporary ocean. Table 2 compares the model output to observations from the Conkright et al. [1994] climatologies of phosphate and silicic acid and to literature estimates from Tyrrell [1999, and references therein] and Tréguer et al. [1995]. Where necessary, outputs have been converted into units of carbon or nitrogen for comparative purposes. In these cases, the standard Redfield C:N:P ratio of 106:16:1 is assumed.

[41] In terms of total primary production and phytoplankton standing stock, the model falls well within literature ranges. The diatom fraction of global production (= diatom fraction of standing stock in the model) is a less well-known quantity. Several estimates for specific locations exist and range from 13 to 34\% [Nelson and Brzezinski, 1997; Blain et al., 1997; Brzezinski et al., 1998], though these estimates do not cover the full range of ocean ecosystems. For instance, Pondaven et al.'s [1998] study of the Southern Ocean estimates that diatoms contribute $37 \%$ of total production. Non-model global estimates are rarer, though a recent survey by Mann [1999] suggested 40 to $45 \%$, somewhat greater than that from the local studies. Scaling Tréguer et al.'s [1995] estimate of biogenic silica production with Redfield ratios of C:N:Si yields an estimate for global production of $19.1 \mathrm{Gt} \mathrm{C} \mathrm{yr}^{-1}$, approximately 38 to $53 \%$ of the total production range shown in Table 2 . However, the variability of the elemental ratios makes this estimate approximate.
[42] The model predictions for silicic acid fluxes compare favorably with those from the Tréguer et al. [1995] budget. Figure 4 shows the comparison between all of the estimated fluxes in Tréguer et al. [1995] with the model. Given that the model's parameterization owes a large amount to Tréguer et al. [1995] this correspondence is perhaps unsurprising. However, since the model includes dynamic and competitive elements not considered in the original budget, this good agreement is partially an emergent property rather than one preordained by parameterization.

[43] The model's predictions for nutrient concentrations and ratios within the two ocean boxes are somewhat less accurate, however. In the surface box, model nutrients are drawn down to much lower levels than found in the Conkright et al. [1994] climatology. This is partially related to the assumption of a 500-m layer throughout which production can occur. In reality, net production rarely takes place below about $100 \mathrm{~m}$ [Littler et al., 1985], and nutrients below this depth are unlikely to be used. Therefore, when the climatology is averaged over the top $500 \mathrm{~m}$, greater nutrient values result. More favorable comparisons may be made by using top 100-m averages from the climatology $\left(P_{s}=0.6 \mathrm{mmol} \mathrm{P} \mathrm{m}{ }^{-3} ; S_{s}=9.0 \mathrm{mmol} \mathrm{Si} \mathrm{m}{ }^{-3}\right)$, and an alternative approach would be to split the ocean model into three layers with a much shallower surface layer in which production could occur (this is examined in section 4.2). The inclusion of light-limited polar latitudes or iron-limited high-nutrient-low-chlorophyll regions would also act to improve nutrient distributions (the latter of these is also examined in section 4.2). In the deep box the comparison between the climatology and the model is more favorable. However, phosphate is still quite different, and this is reflected in the ratio between the nutrients.

[44] From the steady state solution it is clear that "fine tuning" of several parameters would allow a much better fit with the climatology (particularly biological parameters, which are well known to vary widely). However, the intention is only to show that a reasonable fit to the main features of ocean silicon cycling emerges from this simple, first-order model without any tuning.

\subsection{Simulation Results}

[45] To illustrate the results of the preceding steady state analysis, a series of simulations were performed. First, simulations were performed to determine the sensitivity of the model to initial conditions. Figure 5 shows the evolution of deep phosphate and silicic acid in 20 simulations initialized with random nutrient concentrations.

Table 2. Comparison of the Model's Steady State Predictions With Observations

\begin{tabular}{|c|c|c|c|c|}
\hline State Variable or Flux & Units & Model & Literature & \\
\hline Total primary production & $\mathrm{Gt} C \mathrm{yr}^{-1}$ & 46.0 & $36-50$ & [Longhurst et al., 1995; Antoine et al., 1996] \\
\hline Diatom fraction & $\%$ & 45.8 & $13-45$ & {$[\text { Mann, 1999] }]^{\mathrm{a}}$} \\
\hline Total phytoplankton & $\operatorname{Tg} \mathrm{N}$ & 111 & $105-150$ & [Antoine et al., 1996; Schlesinger, 1991] \\
\hline Surface phosphate, $P_{S}$ & $\mathrm{mmol} \mathrm{P} \mathrm{m}{ }^{-3}$ & 0.12 & 1.30 & [Conkright et al., 1994] \\
\hline Surface silicic acid, $S_{s}$ & $\mathrm{mmol} \mathrm{Si} \mathrm{m}^{-3}$ & 1.67 & 20.7 & [Conkright et al., 1994] \\
\hline Deep phosphate, $P_{d}$ & $\mathrm{mmol} \mathrm{P} \mathrm{m} \mathrm{m}^{-3}$ & 1.72 & 2.24 & [Conkright et al., 1994] \\
\hline Deep silicic acid, $S_{d}$ & $\mathrm{mmol} \mathrm{Si} \mathrm{m}^{-3}$ & 118 & 94.8 & [Conkright et al., 1994] \\
\hline Biogenic silica production & Tg Si $\mathrm{yr}^{-1}$ & 7420 & 6720 & [Tréguer et al., 1995] \\
\hline Silica sedimentation & $\mathrm{Tg} \mathrm{Si} \mathrm{yr}^{-1}$ & 186 & 171 & [Tréguer et al., 1995] \\
\hline
\end{tabular}

${ }^{a}$ Also Nelson and Brzezinski [1997] and Blain et al. [1997]. 
Model silicon cycle

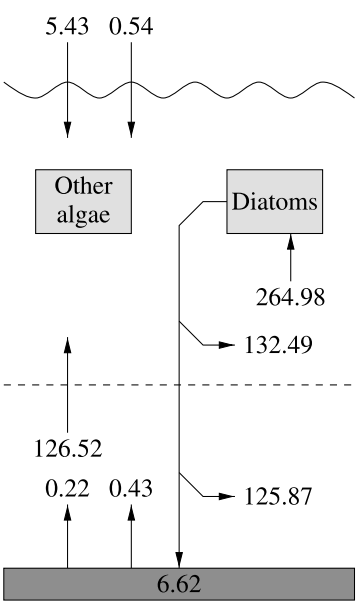

Treguer et al. (1995) silicon cycle

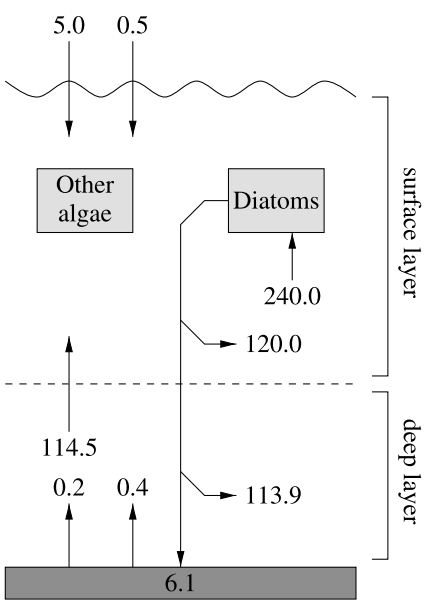

Figure 4. A comparison of the model budget for the global silicon cycle with that of Tréguer et al. [1995]. All fluxes are in Tmol $\mathrm{Si} \mathrm{yr}^{-1}$. The discrepancies in input/output fluxes between the model and the budget are caused by the rounding off of silicic acid input parameter values.

[46] Although there is considerable variation in the time taken to reach steady state, all of the simulations are at, or are closely approaching, the analytical steady state by $200 \mathrm{ky}$. These simulations illustrate the model's stability and insensitivity to initial conditions.

[47] Starting from the model's analytical (and simulated) steady state, the next simulations examine the consequences of increasing the rates of supply of phosphate and silicic acid, respectively, to the model ocean. After $50 \mathrm{ky}$ at the model's steady state, nutrient input rates are increased by $50 \%$. The simulations then proceed for a further $150 \mathrm{ky}$ to examine the consequences of these changes. Figure 6 shows the result of these nutrient additions.
[48] In agreement with the analytical solution, the simulations find that the modeled primary production responds to phosphate addition but not to silicic acid. Silicic acid addition, while shifting the balance in favor of the diatoms, does not alter total primary production. Note that since the diatoms are limited by silicic acid, the benefits of phosphate addition go entirely to the other algae (hence the drop in diatom fraction).

[49] Further simulations (not shown here) involving other changes to the model's parameter set support the findings of the analytical solution. The only exceptions are where changes to the values of the model's parameters are large enough to tip the balance of nutrient limitation in the diatoms from silicic acid to phosphate. Over this threshold the model's behavior shifts radically, leading to the total dominance of the diatoms, the extinction of the other algae, and the resulting loss of feedback controls on the concentration of silicic acid in the ocean.

\section{Sensitivity Analyses}

\subsection{Parameters}

[50] Table 3 shows the results from a parameterby-parameter analysis of the model's sensitivity. For each parameter, values $\pm 25 \%$ the base value are examined to determine the sensitivity of the model's steady state to that parameter. (For the purposes of brevity, only the main silicic acid input to the ocean is examined.)

[51] With the exception of three parameters $\left(\mu_{o}, \mu_{d}\right.$, and $\left.M\right)$, none of the changes made prevent the model from reaching an equilibrium in which both algal groups co-exist and are able to regulate the nutrient cycles. This suggests that this central result is very robust and is not dependent on a finely tuned parameter set.

[52] Changes to these three parameters prevent the model from converging to a steady state by either arranging for the mortality rate to equal or exceed maximum algal growth rate $\left(M \geq \mu_{o} ; M \geq \mu_{d}\right)$, or by making the other algae
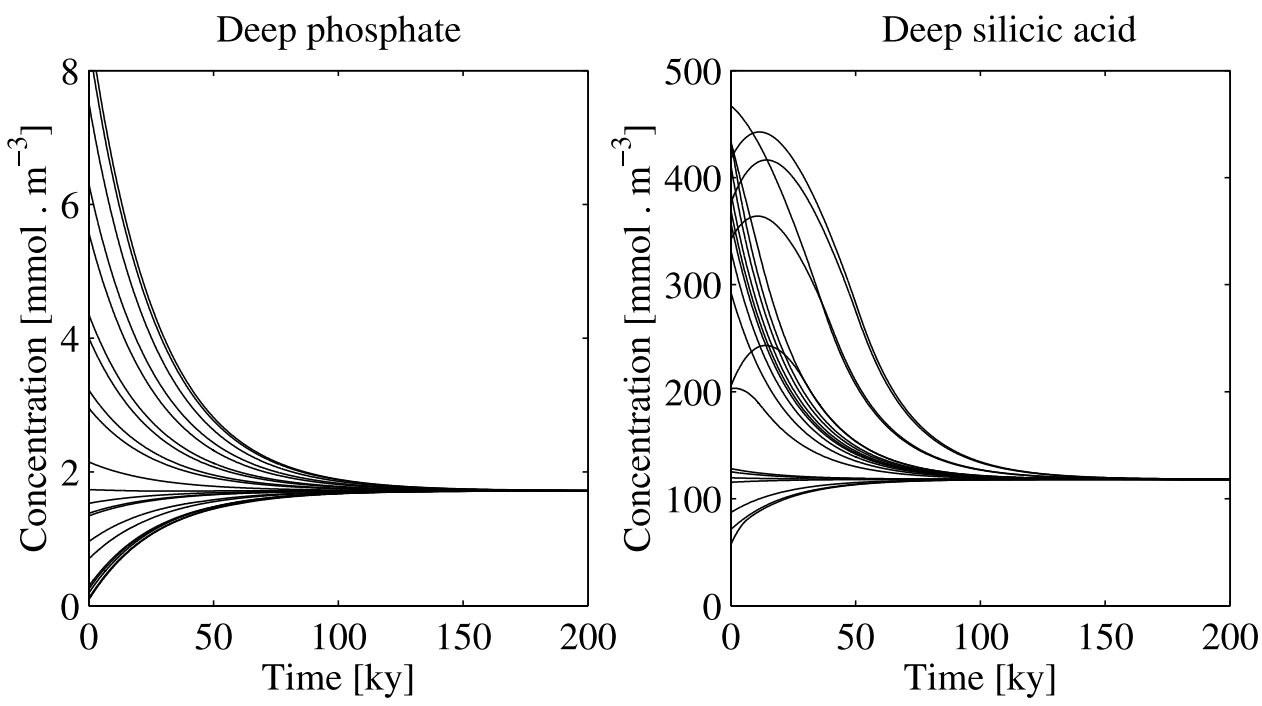

Figure 5. Results of 20 simulations showing the time-evolution of deep phosphate and silicic acid concentrations after they are initialized randomly within the range $0-5$ times steady state values. 

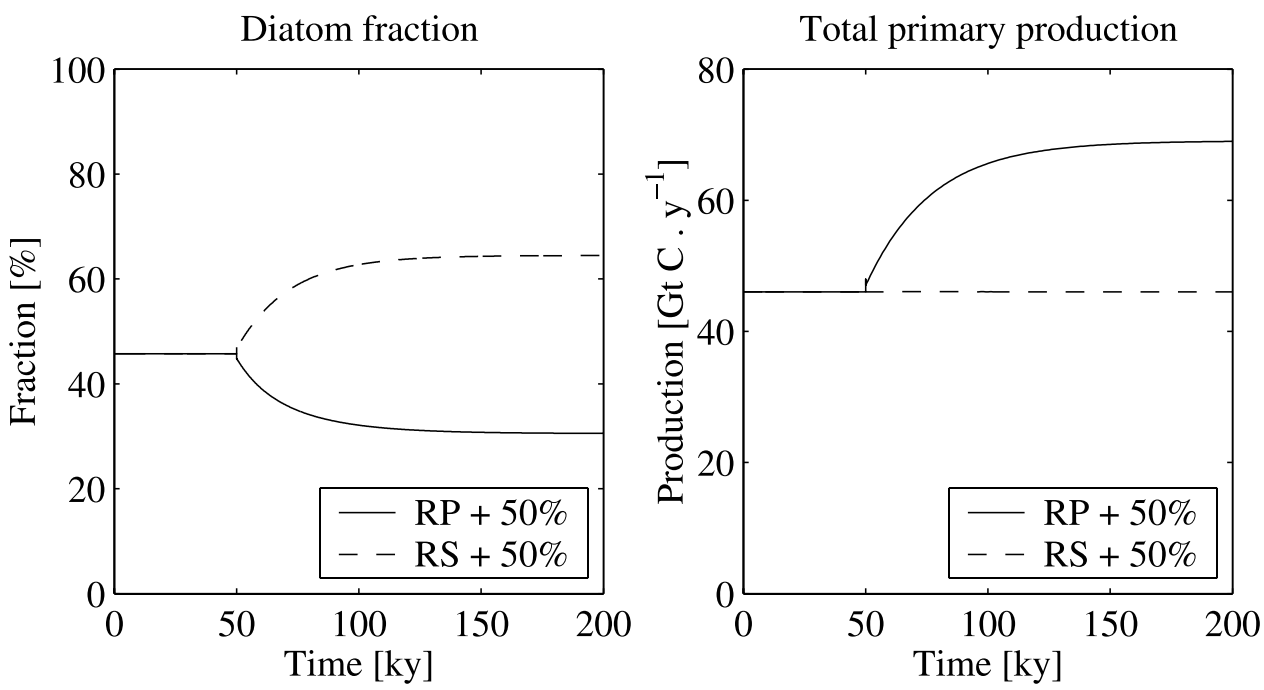

Figure 6. Simulations showing the effects of changes on the supply rate of each nutrient. All model parameters are their baseline values to $50 \mathrm{ky}$. After this point, riverine inputs of both nutrients are separately increased by $50 \%$.

superior to the diatoms $\left(\mu_{o}>\mu_{d}\right)$. From the latter condition, it is apparent that the model results depend critically on the assumption that diatoms are superior competitors (so long as silicic acid is abundant).

\subsection{Processes}

[53] The model is a very simplified representation of the real ocean, in which only the most important processes affecting phosphate and silicic acid concentrations have been included. A series of sensitivity analyses have been carried out to examine the effects of adding processes or changing some of the assumptions in the model.

4.2.1. Tests

[54] 1. Mortality is made density-dependent $(\hat{M}=M \times$ $\left.\frac{O+D}{O^{*}+D^{*}}\right)$ to represent grazing more realistically.
[55] 2. Extra phosphate outputs are added (equal to 0.5 $\times R P)$, decoupled from the organic matter burial, to represent constant export from the ocean in inorganic forms due to apatite formation, adsorption onto iron oxides, et cetera [Ruttenberg, 1993].

[56] 3. Maximum specific growth and mortality rates are increased by factor 3 , to represent faster biological cycling [Banse, 1992].

[57] 4. Phosphate sedimentation rate is coupled to primary production $\left(\hat{S F}=S \hat{F}_{p}=S F \times \frac{T P P}{T P P^{*}}\right)$, to represent burial of a greater fraction of sedimenting material under anoxic conditions [Ingall and Van Capellen, 1990].

[58] 5. Model is converted to three layers $(0-100 \mathrm{~m}$, 100-500 m, 500-3730 m; mixing $2.0 \mathrm{~m} \mathrm{~d}^{-1}$ and $3.0 \mathrm{~m} \mathrm{yr}^{-1}$ at shallower and deeper boundaries; $60 \%$, 35\%, and $4.8 \%$

Table 3. Model Equilibrium Values for a Series of Parameter Sensitivity Analyses ${ }^{\mathrm{a}}$

\begin{tabular}{|c|c|c|c|c|c|c|c|}
\hline Parameter & Total Algae & Diatom Fraction & Surface Phosphate & Surface Silicic Acid & Deep Phosphate & Deep Silicic Acid & TPP \\
\hline Base & 2.740 & 45.8 & 0.120 & 1.667 & 1.720 & 118.2 & 46.0 \\
\hline$S D$ & $3.653,2.192$ & $45.8,45.8$ & $0.120,0.120$ & $1.667,1.667$ & $1.720,1.720$ & $118.2,118.2$ & $61.4,36.8$ \\
\hline$K$ & $2.740,2.740$ & $45.8,45.8$ & $0.120,0.120$ & $1.667,1.667$ & $2.253,1.400$ & $157.0,94.9$ & $46.0,46.0$ \\
\hline$D R$ & $2.740,2.740$ & $45.8,45.8$ & $0.120,0.120$ & $1.667,1.667$ & $1.320,2.120$ & $118.2,118.2$ & $46.0,46.0$ \\
\hline$S F$ & $3.653,2.192$ & $34.3,57.2$ & $0.120,0.120$ & $1.667,1.667$ & $2.253,1.400$ & $118.2,118.2$ & $61.4,36.8$ \\
\hline$D R_{s}$ & $2.740,2.740$ & $45.8,45.8$ & $0.120,0.120$ & $1.667,1.667$ & $1.720,1.720$ & $89.2,147.1$ & $46.0,46.0$ \\
\hline$S F_{s}$ & $2.740,2.740$ & $61.0,36.6$ & $0.120,0.120$ & $1.667,1.667$ & $1.720,1.720$ & $156.8,95.0$ & $46.0,46.0$ \\
\hline$R P$ & $2.055,3.425$ & $61.0,36.6$ & $0.120,0.120$ & $1.667,1.667$ & $1.320,2.120$ & $118.2,118.2$ & $34.5,57.5$ \\
\hline$R S$ & $2.740,2.740$ & $36.4,55.1$ & $0.120,0.120$ & $1.667,1.667$ & $1.720,1.720$ & $94.4,141.9$ & $46.0,46.0$ \\
\hline Rorg & $2.740,2.740$ & $61.0,36.6$ & $0.120,0.120$ & $1.667,1.667$ & $1.720,1.720$ & $118.2,118.2$ & $46.0,46.0$ \\
\hline$\mu_{o}$ &,-- &,-- &,-- &,-- &,-- &,-- &,-- \\
\hline$\mu_{d}$ &,- 2.740 &,- 45.8 &,- 0.120 &,- 0.800 &,- 1.720 &,- 117.3 &,- 46.0 \\
\hline$K_{p}$ & $2.740,2.740$ & $45.8,45.8$ & $0.090,0.150$ & $1.667,1.667$ & $1.690,1.750$ & $118.2,118.2$ & $46.0,46.0$ \\
\hline$\stackrel{P}{K_{s}}$ & $2.740,2.740$ & $45.8,45.8$ & $0.120,0.120$ & $1.250,2.083$ & $1.720,1.720$ & $117.7,118.6$ & $46.0,46.0$ \\
\hline$M$ & $3.653,-$ & $45.7,-$ & $0.045,-$ & $0.682,-$ & $1.645,-$ & 117.2, - & $46.0,-$ \\
\hline
\end{tabular}

${ }^{\mathrm{a}}$ For each parameter, values $25 \%$ below (left) and above (right) the base value were used to examine the consequences to the modeled steady state. The first row contains values from the base model for comparison. The first column lists the parameters in order, as per Table 1 . Note that in the case of the phosphate remineralization and sedimentation parameters, the diatom and other algae parameters are first examined separately and then together. The second and third columns are the total algal concentration $\left(\mu \mathrm{mol} \mathrm{m}{ }^{-3}\right)$ and diatom fraction $(\%)$, respectively. The next four columns list the surface and deep concentrations of phosphate and silicic acid $\left(\mathrm{mmol} \mathrm{m}^{-3}\right)$. The final column presents total oceanic primary production $\left(\mathrm{Gt} \mathrm{C}\right.$ yr $\left.{ }^{-1}\right)$. Gaps $(-)$ in the table indicate parameter values for which no steady state exists. 
phosphate remineralization; $30 \%, 20 \%$, and $47.5 \%$ silica dissolution) to permit separate representation of the euphotic zone from the seasonally mixed zone.

[59] 6. Multiple nutrient limitation of diatom growth rate is changed from Liebig's Law (min $\left[\frac{P_{s}}{P_{s}+K_{p}}, \frac{S_{s}}{S_{s}+K_{s}}\right]$ ) to multiplicative formulation $\left(\frac{P_{s}}{P_{s}+K_{p}} \times \frac{S_{s}}{S_{s}+K_{s}}\right)$ [O'Neill et al., 1989].

[60] 7. Multiplicative limitation is as above, but with diatom maximum specific growth rate increased $\left(\mu_{D}=0.30\right.$ $\mathrm{d}^{-1}$ ) to compensate for the disadvantage from multiplying the two limitations.

[61] 8. Twenty-five percent of mortality is transferred to a semi-labile dissolved organic phosphorus (DOP) reservoir rather than to inorganic nutrient, with $0.27 \% \mathrm{~d}^{-1}(=100 \%$ $\mathrm{yr}^{-1}$ ) of this being remineralized. DOP is mixed between surface and deep boxes in the same fashion as inorganic nutrients.

[62] 9. Phytoplankton mortality is changed from a linear function to a nonlinear grazing term driven by an explicit zooplankton compartment [Fasham et al., 1990].

[63] 10. Effects of iron limitation in the Southern Ocean are added by dividing the ocean into two horizontal regions (Southern Ocean versus the rest of the world) and then limiting both phytoplankton groups in the Southern Ocean region with an implicit iron term [Martin et al., 1990; Pondaven et al., 1998].

[64] 11. Method is as above, except modeling iron explicitly in the Southern Ocean region and including process terms such as upwelling inputs, atmospheric deposition, uptake by phytoplankton, remineralization and scavenging [Fung et al., 2000; Jickells and Spokes, 2001; Ridgwell, 2001; Moore et al., 2002].

[65] 12. In case the advantage diatoms have over the other algae is anti-grazer defense rather than a reduced energetic requirement, diatom advantage over other algae is switched from a fractional growth advantage to a fractional mortality advantage $\left(\mu_{D}=\mu_{O}=0.25 \mathrm{~d}^{-1} ; M_{D}=0.19 \mathrm{~d}^{-1}\right.$; $M_{O}=0.20 \mathrm{~d}^{-1}$ ) [Fryxell and Miller, 1978].

[66] 13. Extending the zooplankton model described above, other algae are assumed to be picophytoplankton and grazed by microzooplankton, while diatoms are assumed to be larger phytoplankton and grazed by mesozooplankton. Other algae growth and mortality parameters modified to represent a faster cycling microbial loop [Furnas, 1990; Dugdale and Wilkerson, 1998].

[67] 14. The quantity of diatom detritus which leaves the surface box before remineralizing is doubled $\left(S R_{p}=90 \%\right)$ to represent faster sinking diatoms [Dugdale and Wilkerson, 1998].

[68] 15. Burial rate of biogenic silica is changed from a fixed fraction to a fraction varying with the rate at which sediments reach the seafloor. Greater rates of sedimentation result in greater rates of burial [Ragueneau et al., 2000].

[69] 16. To represent the frustule-thinning processes observed when diatoms are silicic acid-stressed [Flynn and Martin-Jézéquel, 2000], the variable diatom Si:P ratio, $\hat{R}_{\text {org }}$, is modified such that values lower than $R_{\text {org }}$ are possible. The advantage of this for diatoms is offset by an increased mortality rate, representing the loss in frustule integrity caused by their thinning [Hamm et al., 2003].
Further details for these sensitivity analyses can be found in Appendix A.

\subsubsection{Results}

[70] Table 4 shows system properties for the equilibria reached for each of these sensitivity tests. In each case it was first checked that the model reached a stable equilibrium, since extinction of either or both of the algal groups can render the model unstable. However, in all of the cases examined here, the model converged to stable equilibria.

[71] While the majority of the tests reach different equilibria to that of the base model, in most cases the differences are very slight (TPP was different in only a single, predictable case). In those tests with exactly the same equilibrium as that of the base model (tests 1, 4, and 15), the modifications to the model provide additional negative feedback loops which essentially accelerate the model's progress to equilibrium and cancel when it is reached.

[72] 1. The addition of density-dependent mortality provides a degree of negative feedback on phytoplankton concentrations. When concentrations are higher, mortality rates are greater and vice versa, causing the model to more rapidly approach equilibrium. Since the density-dependence term effectively cancels at equilibrium, the model's equilibrium is unchanged.

[73] 2. Including extra phosphate outputs that operate at a constant rate and are uncoupled from the biogeochemistry effectively adds an additional sink for phosphate in the ocean. Since riverine input is unchanged, TPP falls to compensate (diatom fraction rises as the other algae are squeezed by decreased phosphate availability).

[74] 3. Accelerating the rates of the model's biological processes decreases the standing stocks of phytoplankton, but leaves TPP unaffected. This is to be expected since nutrient inputs and outputs remain unchanged. Surface nutrient concentrations are unchanged because growth and mortality rates are accelerated by the same factor.

[75] 4. In the same fashion as test 1, tying the phosphate burial fraction to TPP acts as an additional negative feedback loop. High TPP leads to deep anoxia and increases burial, while decreased TPP lowers deep anoxia and decreases burial. Again, the modified term acts to accelerate approach to equilibrium and cancels upon reaching it.

[76] 5. Separating the euphotic and seasonally mixed layers primarily allows the model to better represent the vertical distribution of both nutrients, though concentrations are still lower than those observed. Phytoplankton concentrations are raised, though this is entirely due to their confinement in a thinner ocean layer (diatoms and other algae occur in the same proportions as the base model). Although these concentrations have changed, fluxes such as TPP remain unchanged.

[77] 6. The primary effect of adopting a multiplicative nutrient relationship is increased silicic acid concentrations in both ocean boxes. Total phytoplankton concentration and TPP are unchanged by this modification, although the diatom fraction falls in response to the reduction in their growth rate caused by the multiplicative form. Since multiplying both limitations always results in a value lower than either limitation, $\hat{R}_{\text {org }}$ assumes a value greater than $R_{\text {org }}(=20)$. 
Table 4. Model Equilibrium Values for a Range of Sensitivity Analyses $^{\mathrm{a}}$

\begin{tabular}{|c|c|c|c|c|c|c|c|}
\hline Test & $\begin{array}{r}\text { Total } \\
\text { Algae } \\
\end{array}$ & $\begin{array}{c}\text { Diatom } \\
\text { Fraction }\end{array}$ & $\begin{array}{c}\text { Surface } \\
\text { Phosphate }\end{array}$ & $\begin{array}{c}\text { Surface } \\
\text { Silicic } \\
\text { Acid }\end{array}$ & $\begin{array}{c}\text { Deep } \\
\text { Phosphate }\end{array}$ & $\begin{array}{c}\text { Deep } \\
\text { Silicic } \\
\text { Acid }\end{array}$ & TPP \\
\hline Base & 2.740 & 45.8 & 0.120 & 1.667 & 1.720 & 118.2 & 46.0 \\
\hline 1 & 2.740 & 45.8 & 0.120 & 1.667 & 1.720 & 118.2 & 46.0 \\
\hline 2 & 1.370 & 91.4 & 0.120 & 1.667 & 0.887 & 118.2 & 23.0 \\
\hline 3 & 9.132 & 45.8 & 0.120 & 1.667 & 1.720 & 118.2 & 46.0 \\
\hline 4 & 2.740 & 45.8 & 0.120 & 1.667 & 1.720 & 118.2 & 46.0 \\
\hline 5 & 13.70 & 45.8 & 0.120 & 1.667 & 1.775 & 118.8 & 46.0 \\
\hline 6 & 2.740 & 36.6 & 0.120 & 12.50 & 1.720 & 129.0 & 46.0 \\
\hline 7 & 2.740 & 36.6 & 0.120 & 2.500 & 1.720 & 119.0 & 46.0 \\
\hline 8 & 2.740 & 45.8 & 0.120 & 1.667 & 1.353 & 118.2 & 46.0 \\
\hline 9 & 2.785 & 45.8 & 0.111 & 1.556 & 1.711 & 118.1 & 46.0 \\
\hline \multirow[t]{2}{*}{$10^{\mathrm{b}}$} & 1.089 & 52.4 & 0.449 & 11.92 & 1.824 & 118.9 & 2.3 \\
\hline & 3.122 & 45.3 & 0.204 & 1.550 & 1.860 & 120.4 & 43.7 \\
\hline \multirow[t]{2}{*}{$11^{\mathrm{b}}$} & 2.125 & 41.3 & 0.602 & 10.43 & 1.838 & 118.6 & 5.3 \\
\hline & 2.964 & 46.3 & 0.203 & 1.313 & 1.894 & 119.9 & 40.7 \\
\hline 12 & 2.805 & 47.0 & 0.120 & 1.583 & 1.720 & 118.1 & 46.0 \\
\hline 13 & 2.539 & 60.3 & 0.056 & 0.850 & 1.656 & 117.3 & 46.0 \\
\hline 14 & 2.740 & 45.8 & 0.120 & 1.667 & 2.482 & 118.2 & 46.0 \\
\hline 15 & 2.740 & 45.8 & 0.120 & 1.667 & 1.720 & 118.2 & 46.0 \\
\hline 16 & 2.734 & 46.2 & 0.116 & 1.760 & 1.716 & 118.3 & 46.0 \\
\hline
\end{tabular}

${ }^{\mathrm{a}}$ The first row contains values from the base model for comparison. The first column lists the test numbers as per the preceding text. The second and third columns are the total algal concentration $\left(\mu \mathrm{mol} \mathrm{m} \mathrm{m}^{-3}\right)$ and diatom fraction (\%), respectively. The next four columns list the surface and deep concentrations of phosphate and silicic acid $\left(\mathrm{mmol} \mathrm{m}^{-3}\right)$. The final column

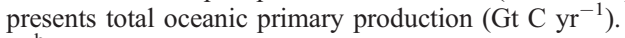

bIn these sensitivity analyses the model's geographical domain is split into two horizontal regions: the Southern Ocean ( $20 \%$ by volume) and the rest of the world. Correspondingly, the results are presented separately for the two regions (the iron-limited Southern Ocean is given first).

[78] 7. As above, but silicic acid concentrations more closely resemble those of the base model. Diatom fraction and $\hat{R}_{\text {org }}$ are still affected by the multiplicative term.

[79] 8. The addition of DOP has a minor effect on the model. Deep phosphate concentration falls slightly, but otherwise the model behaves similarly to the base model. At equilibrium $0.6 \%$ of the total phosphate inventory is in the dissolved organic pool, although almost $30 \%$ of the surface inventory is DOP.

[80] 9. Surprisingly, given the important role of zooplankton in many ecosystem models, the addition of an explicit zooplankton compartment only marginally affects model equilibrium and behavior (due partially to the lack of seasonality in the model). Nutrient and phytoplankton concentrations are slightly altered, but TPP is unchanged. However, in simulations the zooplankton do accelerate the model's progress to equilibrium.

[81] 10. See section 4.2.3.

[82] 11. See section 4.2.3.

[83] 12. Switching diatom advantage from growth to mortality has no significant effect on the model. The equilibrium values of nutrient and phytoplankton concentrations are slightly different from those of the base model, but these differences are simply due to the new relative differences between growth and grazing rates.

[84] 13. Similarly to the results of the single zooplankton model described earlier, the extension of the model to explicitly consider grazing by microzooplankton and mesozooplankton does not markedly alter the model equilibrium or its dynamical behavior. In common with test 3 , the acceleration of the growth and mortality rates of the other algae and their microzooplankton grazers results in a decrease in their concentrations. This can be seen in the increased diatom fraction of biomass shown in the table. However, the diatom fraction of production is almost unchanged from that of the base model. In the same way, TPP and other fluxes are broadly unaffected.

[85] 14. Increasing diatom sinking speed increases the export of organic phosphorus from the surface box, resulting in higher concentrations of phosphate in the deep box. However, the results of this sensitivity analysis are otherwise the same as that of the base model. Section 5 contains a more detailed analysis of this model change.

[86] 15. Similarly to test 4, varying the burial fraction of biogenic silica with sedimentation rate acts as a further negative feedback on the model's dynamics. The greater the rate at which material reaches the seafloor, the greater the rate at which it is buried and removed from the model system, and vice versa. At equilibrium the variable rate converges to the same value as that of the base model, so the equilibrium states are identical.

[87] 16. As diatoms are most limited by silicic acid at the base model's equilibrium state, permitting diatoms to reduce their $\mathrm{Si}: \mathrm{P}$ ratio should change the equilibrium state. However, since diatom mortality rises with decreasing $\mathrm{Si}: \mathrm{P}$ the changes are quite marginal. The increase in diatom competitiveness allows them to slightly draw down surface phosphate concentrations with a resulting drop in total phytoplankton concentration, but with a small gain in diatom fraction. Silicic acid concentrations rise slightly with the removal of the minimum $\mathrm{Si}: \mathrm{P}$ ratio, and at equilibrium $\hat{R}_{\text {org }}=$ 15.68. Taken as a whole, these sensitivity analyses show that the ability of phytoplankton competition in the model to control both nutrient cycles is robust and not sensitive to most assumptions about parameters and processes.

\subsubsection{Iron Biogeochemistry}

[88] In the case of the sensitivity analyses examining iron limitation of phytoplankton growth, both of the modified models are able to successfully reproduce high-nutrientlow-chlorophyll (HNLC) conditions in their Southern Ocean regions. Further, as would be expected under iron limitation, both models find the $\mathrm{Si}: \mathrm{P}$ ratio in the Southern Ocean to be considerably greater (23.5 and 33.0, respectively) than that in the iron-replete region (and in the ironreplete models of the other sensitivity analyses).

[89] HNLC conditions produced by these analyses are caused by the model parameterizations reducing the uptake of both phosphate and silicic acid and leaving large quantities unutilized. Si:P ratios in the diatoms are raised in these models by the effect of iron limitation on cell cycle duration. Low availability of iron extends diatom division cycles, giving them longer periods of time to accumulate silica in their frustules and to increase cell silicon content. TPP in both models is unchanged from that of the base model: While production falls in the Southern Ocean, it rises in the rest of the world to make use of the surplus nutrients (note though that this is an equilibrium result, TPP can be affected transiently for relatively long periods of time by changes to the iron cycle). 
[90] As regards surface nutrient concentrations, in the real Southern Ocean these are elevated above those of the rest of the world by approximately factor 4 (both phosphate and silicic acid). While these ratios fall between $2-3$ for phosphate and 7-8 for silicic acid in the two models used here, it is clear from analytical solutions that the models can be tuned to produce better agreement with observations. However, given the incomplete understanding of the processes that govern iron biogeochemistry, such a tuning exercise has not been undertaken with the simple models explored here.

\section{Silica Pump}

\subsection{Remineralization}

[91] As remarked upon earlier, the diatoms are especially important biogeochemically because of their major contribution to the biological pump of carbon from the surface waters to the interior of the ocean. Their contribution is enhanced primarily by two features of their ecology: (1) When they encounter unfavorable growing conditions (e.g., the depletion of silicic acid), many diatom species aggregate and sink from the surface mixed layer [Smetacek, 1985; Thibault et al., 1999; Engel et al., 2002], and (2) their grazing by mesozooplankton produces relatively large and fast-sinking faecal pellets [Frangoulis et al., 2001]. Appreciation of the role of diatom sinking fluxes to ocean biogeochemistry is increasing, and recent theoretical work has highlighted the importance of biogenic opal in ballasting and protecting sinking material [Armstrong et al., 2002].

[92] This importance of diatoms to the transport of carbon, coupled with their utilization of silicic acid, has led to the proposal of the "silica pump" hypothesis [Dugdale and Wilkerson, 1998]. In this hypothesis, the export of biogenic material (i.e., carbon, nitrogen, and phosphorus) from the mixed layer is intimately coupled to silica export by the activity of the diatoms. Export continues until silicic acid is depleted, after which biological activity in the mixed layer is dominated by the microbial loop which regenerates nutrients more efficiently and exports at a much reduced rate. Since the cycles of the other phytoplankton macronutrients are also tied to the "silica pump," the hypothesis argues that silicic acid effectively drives "new" production in the relevant ocean regions.

[93] While skewing the dissolution of biogenic silica towards the deep ocean, the base parameterization of the model assumes that phosphorus is remineralized identically between the two algal groups. Model diatoms, therefore, do not affect "new" production in the fashion proposed by the "silica pump." However, it is simple to modify the model to account for differing remineralization profiles, and only the surface and deep phosphate equations are affected. The modified equations become

$$
\begin{aligned}
\frac{d P_{s}}{d t}= & -\left[\mu_{O} \cdot \frac{P_{s}}{P_{s}+K_{p}} \cdot O\right]-\left[\mu_{D} \cdot \min \left(\frac{P_{s}}{P_{s}+K_{p}}, \frac{S_{s}}{S_{s}+K_{s}}\right) \cdot D\right] \\
& +[S R \cdot M \cdot O]+\left[S R_{p} \cdot M \cdot D\right]+\left[K \cdot \frac{P_{d}-P_{s}}{S D}\right]+\left[\frac{R P}{S D}\right]
\end{aligned}
$$

$$
\begin{aligned}
\frac{d P_{d}}{d t}= & +\left[D R \cdot M \cdot O \cdot \frac{S D}{D D}\right]+\left[D R_{p} \cdot M \cdot D \cdot \frac{S D}{D D}\right] \\
& -\left[K \cdot \frac{P_{d}-P_{s}}{D D}\right]
\end{aligned}
$$

With these equations come two new parameters, $S R_{p}$ and $D R_{p}$ (assuming that phosphate sedimentation is unaffected; i.e., $S R_{p}+D R_{p}+S F=100 \%$ ), which allow the remineralization profile of diatom phosphate to be specified independently from that of other algae phosphate. Given these new equations and parameters, the analytical solution for the model at steady state can be recalculated. While the majority of the equations for equilibrium state variables and properties are unchanged, export and deep phosphate concentrations are both affected by the introduction of the new parameters,

$$
\text { Export }=\frac{(1-S R)}{S D} \cdot \frac{R P}{S F}+\frac{\left(S R-S R_{p}\right)}{S D} \cdot \frac{(R S+A S+H S+W S)}{S F_{S} \cdot R_{\text {org }}}
$$

$P_{d}^{*}=P_{s}^{*}+\frac{1}{K} \cdot\left[\frac{D R \cdot R P}{S F}+\left(D R_{p}-D R\right) \cdot \frac{(R S+A S+H S+W S)}{S F_{s} \cdot R_{\text {org }}}\right]$.

Unsurprisingly, increasing the fraction of diatom phosphate remineralized at depth has the primary effect of increasing nutrient export from the model's surface layer. However, at equilibrium, TPP is unaffected by this enhanced transfer of nutrient, since the export is offset by higher deep phosphate concentrations and, consequently, a greater upwelling flux of phosphate. Effectively, the diatoms increase "new" production by more efficiently transferring phosphate to the deep ocean, but without affecting the total quantity of oceanic production. Figure 7 shows the behavior of export and deep phosphate across a range of $S R_{p}$.

[94] However, this is an equilibrium result. Shifts in diatom numbers will still affect TPP until steady state is re-established. Figure 8 shows such results from two simulations in which diatom abundance is perturbed with transitory effects on their numbers and on TPP. In both of these simulations, diatoms export phosphate from the surface box at twice the efficiency of other algae $(S R=95 \%$, $S R_{p}=90 \%$; i.e., diatom export is twice the fraction of that of other algae). As the simulations show, although TPP ultimately re-equilibrates to the same steady state, transient behavior can take many ky. In the short term, shifts in diatom numbers may noticeably increase or decrease TPP.

\subsection{Sedimentation}

[95] The discussion above describes changes to the model's results caused by shifting the proportions of detrital diatom phosphate remineralized in the surface and deep boxes. Given that detritus produced by the model diatoms is assumed to be sinking faster, it might be expected that this would lead to a concomitant increase in the quantity of detrital diatom phosphate which reaches the seafloor and is buried. 

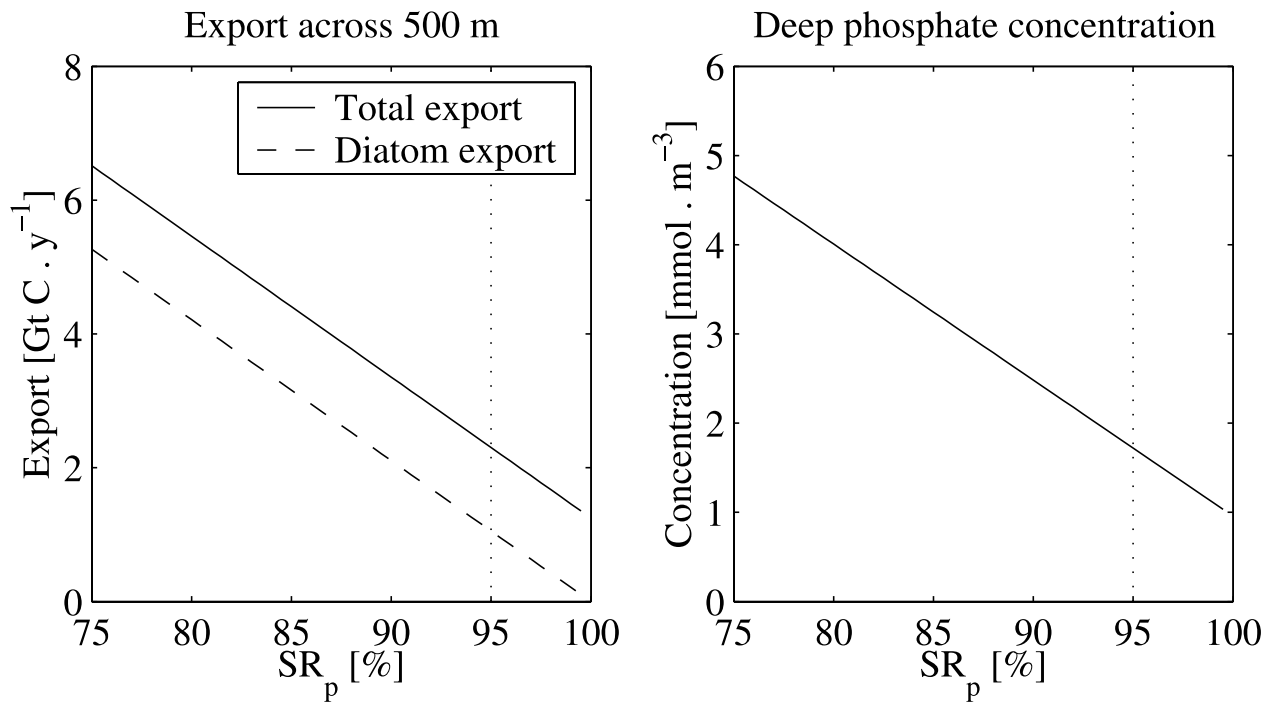

Figure 7. Equilibrium values of export across $500 \mathrm{~m}$ and deep phosphate concentration over a range of diatom surface remineralization fraction $\left(S R_{p}\right)$. The dotted line marks the baseline value, where diatom and other algae share the same fraction.

[96] This requires no change to the model equations shown above, but only a new (implicit) parameter, $S F_{p}$, to distinguish the phosphate sedimentation fraction of diatoms from that of other algae. The values of parameters $S R_{p}$ and $D R_{p}$ need to be altered such that $\left(S R_{p}+D R_{p}+S F_{p}\right)=100 \%$.

[97] The introduction of this modification causes significant changes to the model's steady state equations. The most important of these is the change to TPP,

$$
\begin{aligned}
\mathrm{TPP} & =\frac{R P}{S D \cdot S F}-\left(\frac{S F_{p}}{S F}-1\right) \cdot \frac{(R S+A S+H S+W S)}{S D \cdot S F_{s} \cdot R_{\text {org }}} \\
& =\frac{R P}{S D \cdot S F}-\left(\frac{S F_{p}}{S F}-1\right) \cdot M \cdot D^{*}
\end{aligned}
$$

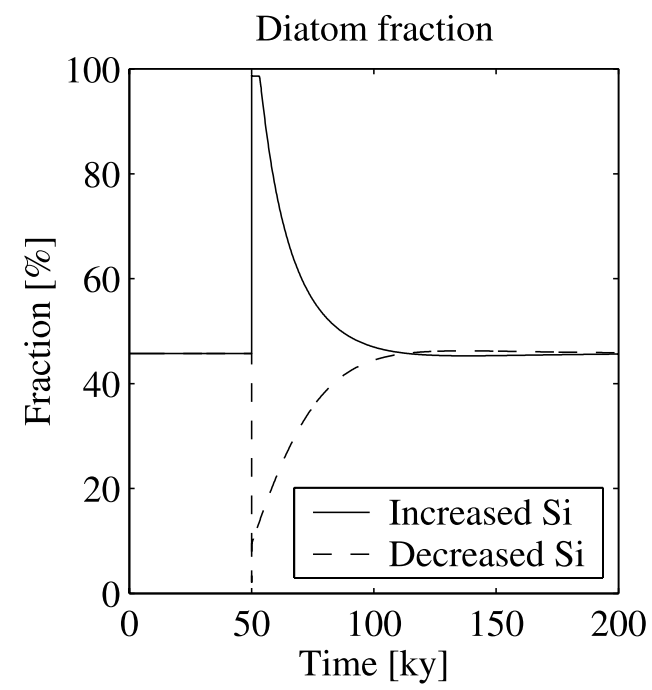

Previously, TPP was affected solely by changes to phosphate parameters. However, distinguishing between the sedimentation processes of the diatoms and the other algae now ties the silicon cycle to that of phosphate, and enables the diatoms to exert an influence on TPP.

[98] Assuming that $S F_{p}>S F$ (i.e., a greater fraction of diatom material reaches the seafloor and is buried), the new steady state equation for TPP suggests that ocean productivity varies inversely with diatom success. For instance, changes to the model system which favor diatoms (e.g., increasing silicic acid supply to the ocean) decrease TPP, since phosphate is more efficiently buried. Figure 9 shows the behavior of TPP and phytoplankton concentrations over a range of $S F_{p}$ (including values at which $S F_{p}<$

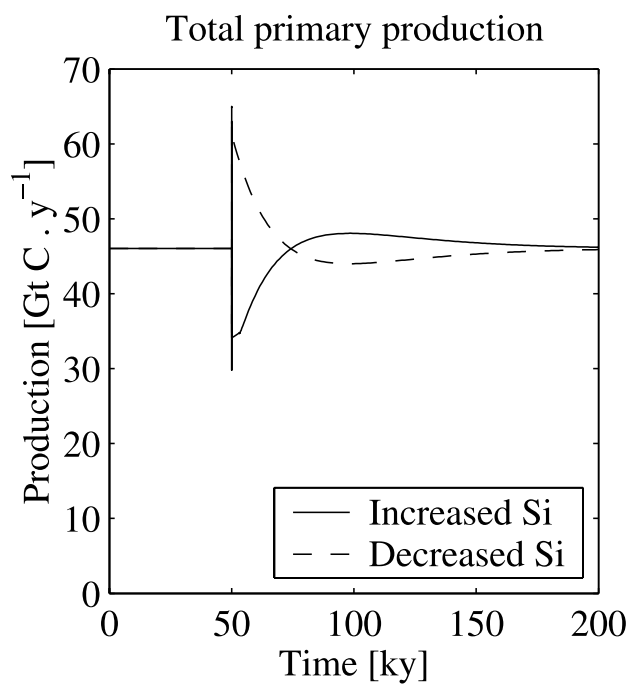

Figure 8. Model simulated at equilibrium to $50 \mathrm{ky}$. After this point, deep silicic acid conditions perturbed $( \pm 75 \%)$ to induce a diatom response. Plots show the time evolution of (left) diatom fraction and (right) TPP following the perturbation. Throughout simulation, $S R=95 \%, S R_{p}=90 \%$. 
$S F)$. As can be seen from the latter plot, although diatom concentration at equilibrium does not vary across the range of $S F_{p}$ shown, the diatom fraction of total phytoplankton rises with increasing $S F_{p}$, as the diatoms constrict phosphate supply (by increasing its burial) and narrow the niche available to the other algae.

[99] Recent theoretical work by Armstrong et al. [2002] has emphasized the importance of dense material, such as biogenic opal, acting as "ballast" in sinking organic matter. In order to examine the global implications of this work, Klaas and Archer [2002] processed sediment trap data from around the world to determine the fluxes of organic carbon to the deep ocean (and seafloor) carried by biogenic opal, calcium carbonate, and lithogenic material. Their results suggest that the majority of organic carbon reaching the seafloor does so in association with calcium carbonate rather than biogenic opal ( $80-83 \%$ versus $11-15 \%$, respectively). Assuming that there are no large systematic biases in the C:P ratio in detritus ballasted by these different materials, this result suggests that the earlier assumption of $S F_{p}>S F$ is simplistic, or even incorrect. For instance, were all calcium carbonate to be produced by the other algae (which include coccolithophorids) it would be more reasonable for $S F_{p}<S F$ (in which case, the greater the diatom fraction, the greater TPP). However, given that calcium carbonate is produced by both phytoplankton and zooplankton, and that diatoms are consumed by zooplankton which utilize calcium carbonate, it is difficult, at this stage, to parameterize $S F_{p}$ and $S F$ confidently (given the simplicity of the model, it may not prove practicable). However, the model analysis here serves to indicate a potential pathway by which the silicon cycle may be tied to that of phosphorus and may directly influence oceanic TPP.

[100] It is worth noting in passing that even if $S F_{p} \leq S F$, then $S R_{p} \geq S R$ is not in any way precluded. It is still perfectly possible for the majority of export across the permanent thermocline to be driven by biogenic opal, while the majority of material reaching the seafloor is associated with calcium carbonate. As noted by Klaas and Archer [2002], calcium carbonate is denser than biogenic opal, enabling it to sink faster, and thereby reducing the time available for remineralization before the sinking material reaches the seafloor.

\section{Discussion}

[101] Following on from the work of Tyrrell [1999], this study has aimed to shed light onto how ecological interactions between rival phytoplankton groups can lead to regulation of the ocean's silicon cycle. Whereas Tyrrell [1999] studied nitrate and phosphate, the work here has examined the ocean's biogeochemical cycles of silicic acid and phosphate.

[102] A simple model has been developed incorporating both phosphate and silicic acid, and with two phytoplankton groups, diatoms and other algae, to compete for the phosphate. Parameterization of this model, primarily using the estimated silicon budget of Tréguer et al. [1995], produces a system which agrees reasonably well with observations and in which both nutrients are controlled through competition between the phytoplankton. While the slightly superior model diatoms should, in principle, drive the other algae to extinction, the supply of silicic acid to the ocean from exterior sources is, relative to that of phosphate, insufficient to allow them to do so. Modeled diatom populations are held in check by silicic acid availability, and the other algae fill the large gap left open to them so that they are numerically dominant. The cycles of both nutrients are thus regulated by phytoplankton activity: the diatoms both controlling and limited by silicic acid; the sum of both algal groups both controlling and limited by phosphate.

[103] This model has been used to address two key questions concerning the operation of the silicon cycle in the contemporary ocean. The first, whether switches between siliceous and non-siliceous phytoplankton can control the silicon cycle, is answered in the affirmative. The ecological success of diatoms varies inversely with the concentration of silicic acid, providing negative feedback that controls the silicon cycle. This is in agreement with earlier speculations [Broecker and Peng, 1982; Siever, 1991] as to the importance of diatoms in regulating the oceanic silicon cycle, but this time in an explicit, quantitative ecological/biogeochemical model, which is grounded in recent work on diatoms and the silicon cycle.

[104] The second question concerns the effects of these ecological switches on ocean productivity and the export flux of organic material to the ocean's interior. The base model finds that total primary production in the ocean is limited by the availability of phosphate but not silicic acid. Increases or decreases in the availability of silicic acid merely shift the balance of production between the diatoms and the other algae, without any effect on total production. However, it is still the case that silicic acid is the proximate limiting nutrient for diatoms in surface waters (in a Liebig's law sense). Phosphate is the ultimate limiting nutrient, consistent with Tyrrell's [1999] finding with a nitrate/ phosphate model. The parameterization of the base model means that export flux is similarly unaffected by the composition of the modeled phytoplankton community.

[105] One caveat to these results is that the base model contains many simplifications of known elements of the silicon cycle, as well as entirely excluding many other elements. However, as the sensitivity analyses aim to show, the general results are resilient to modifications and improvements to the model. Extension of the model, for instance by adding DOM, zooplankton or even iron limitation, does not much alter the model's equilibrium behavior from that of its base form. Some modifications (e.g., density dependent mortality; tying sedimentation to anoxia; variable silica burial) even act to increase the strength of negative feedback loops within the model.

[106] This does not apply to all additions of complexity to the model. In order to examine the "silica pump" hypothesis [Dugdale and Wilkerson, 1998], the diatom submodel was reparameterized to represent a greater transport of diatom detritus to the deep ocean (relative to that of the other algae). In contrast to the results of the base model, this parameterization finds that (at equilibrium) the export flux varies proportionately with diatom success. Increases or 

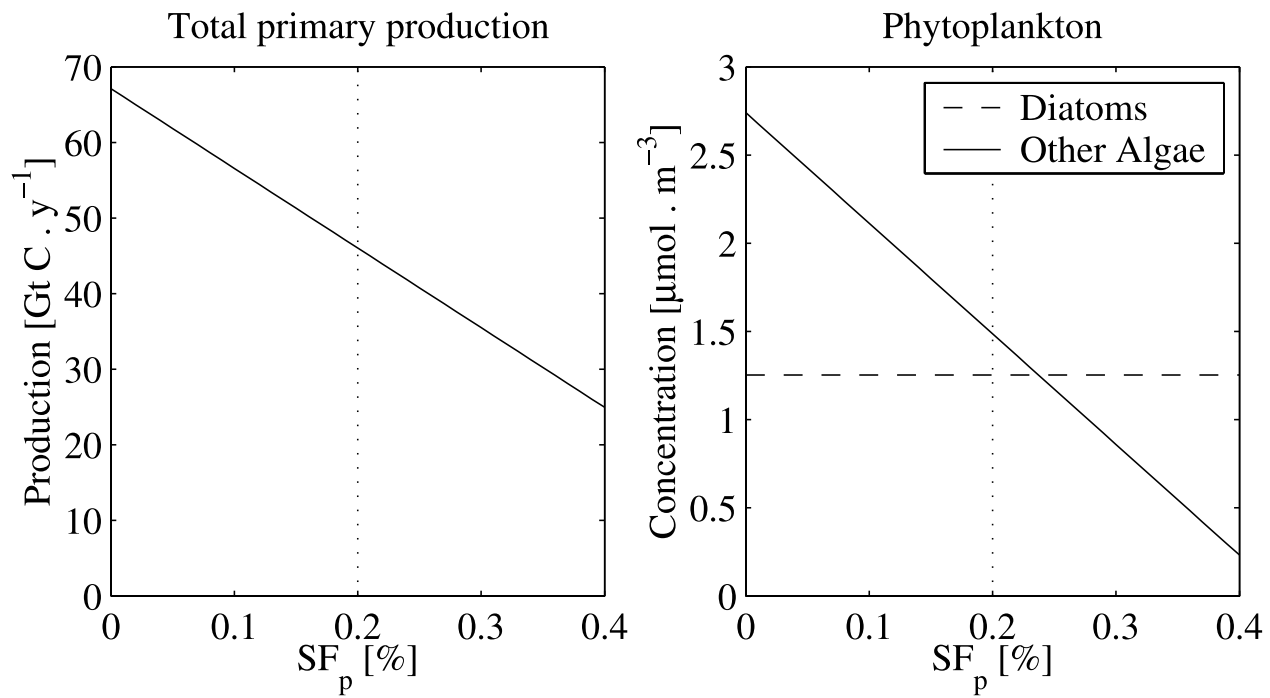

Figure 9. Equilibrium values of (left) TPP and (right) phytoplankton concentrations over a range of diatom sedimentation fraction $\left(S F_{p}\right)$. The dotted line marks the baseline value, where diatom and other algae share the same fraction.

decreases in the availability of silicic acid now directly affect the export flux. However, although the diatoms now transport nutrients to the deep ocean at a greater rate, total production is unaffected since the greater export is offset by a greater upwelling flux of nutrients.

[107] Extending this analysis further to the fraction of detrital material which is buried at the seafloor reveals a pathway by which the diatoms may directly tie the activity of the phosphate cycle (and TPP) to that of the silicon cycle. Depending upon assumptions about the mechanism (or mechanisms) by which organic material reaches the seafloor, it is possible for the model diatoms to have a direct means by which to regulate TPP. The sensitivity of the model to this aspect of its formulation underscores the necessity for greater understanding of the processes of remineralization and burial (at least for long-term or Earth history studies).

[108] As a side note, changes to the silicon cycle in reality (most noticeably in freshwater and coastal habitats) can lead to other significant changes to ecosystems. Reduction in silicic acid, either through modifications to its supply or its removal (e.g., eutrophication with nitrate or phosphate; construction of dams) is known to favor non-siliceous species, occasionally nuisance or toxic species [Humborg et al., 1997]. Further, reduction in diatom importance can lead to a greater degree of nutrient trapping in surface waters (i.e., a reversal of the "silica pump") [Dugdale and Wilkerson, 1998] with a concomitant increase in nonsiliceous phytoplankton concentrations, and a decrease in water transparency. A reduction in diatoms can also lead to a reduction in export flux and, interestingly, a decrease in anoxia as less material to be remineralized reaches the seafloor. Conley et al. [1993] review the significance of these and other changes to biogeochemistry resulting from reduction in the availability of silicic acid.

[109] As well as examining the contemporary silicon cycle, this quantitative model can be used to evaluate geological hypotheses about the operation of the cycle in the Earth's past (e.g., opal deposition events during the Cenozoic Era) [McGowran, 1989]. Extending the model in this direction will form the subject of a future paper.

\section{Conclusions}

[110] 1. A simple two-box biogeochemical model describing the ocean cycles of phosphorus and silicon has been developed. Biological components are restricted to two functional groups of phytoplankton: diatoms and other algae.

[111] 2. Competition between silicic acid-requiring diatoms and other algae allows the model to regulate both the silicon and phosphorus cycles. Fluxes and steady state concentrations are in reasonable agreement with observations. The competitive superiority of the diatoms (either in terms of increased growth or decreased mortality rates) is a critical assumption, without which the silicon cycle would not be controlled by the model.

[112] 3. Despite this superiority, the other algae are able to persist, and to dominate numerically, because the supply of silicic acid to the ocean is insufficient for total diatom dominance.

[113] 4. Total primary production is affected solely by the availability of phosphate. Changes in the supply rate of silicic acid to the ocean do not affect primary production, although they do affect the proportion of production that is diatom based.

[114] 5. The model's general results are unaltered by almost all modifications to its parameters and structure. Some modifications to the silicon cycle suggested in the literature add additional negative feedback loops to the model and accelerate the model towards its steady state in simulations.

[115] 6. Changes to model's parameterization to represent the "silica pump" hypothesis (i.e., increased diatom sinking 
relative to other algae) increase "new" production. This increase in export of organic phosphate to the deep ocean is offset by higher deep phosphate concentrations and a greater upwelling flux of phosphate.

[116] 7. Extending these changes to phosphate burial fractions indicates how diatoms may tie the two nutrient cycles (and total primary production) together. However, an incomplete understanding of detrital sinking and remineralization, together with the simplicity of the model (e.g., its exclusion of calcifying phytoplankton/zooplankton), preclude strong predictions from this finding.

\section{Appendix A: Sensitivity Analyses}

\section{A1. Density-Dependent Mortality}

[117] Both phytoplankton mortality terms are modified to include reference to steady state phytoplankton biomass. This has the effect of decreasing grazing pressure at low phytoplankton biomass and increasing it when phytoplankton concentration exceeds its equilibrium value.

$$
\begin{aligned}
& \frac{d O}{d t}=\ldots-\left[M \cdot \frac{(O+D)}{\left(O^{*}+D^{*}\right)} \cdot O\right] \\
& \frac{d D}{d t}=\ldots-\left[M \cdot \frac{(O+D)}{\left(O^{*}+D^{*}\right)} \cdot D\right] .
\end{aligned}
$$

\section{A2. Extra Phosphate Outputs}

[118] In a similar fashion to which phosphate enters the model system, the surface phosphate equation is modified to include a constant loss rate to represent loss of phosphate due to apatite formation, adsorption onto iron oxides, etc.

$$
\frac{d P_{S}}{d t}=\ldots+\left[\frac{R P}{S D}\right]-\left[\frac{L P}{S D}\right]
$$

where

$$
L P=\frac{R P}{2}
$$

\section{A3. Faster Biological Cycling}

[119] This modification to the model simply involves increases to the biological rate processes (growth and mortality).

\section{A4. Variable Phosphate Sedimentation Rate}

[120] The fraction of detrital phosphate which is buried and permanently removed from the model system is made a simple function of total primary production and equilibrium production. Since production consumes oxygen in the deep ocean, high levels of production (i.e., above equilibrium) are assumed to deplete the deep ocean of oxygen and reduce deep remineralization.

$$
\begin{aligned}
\frac{d P_{d}}{d t}= & +\left[\hat{D R} \cdot M \cdot O \cdot \frac{S D}{D D}\right]+\left[\hat{D R_{p}} \cdot M \cdot D \cdot \frac{S D}{D D}\right] \\
& -\left[K \cdot \frac{P_{d}-P_{s}}{D D}\right],
\end{aligned}
$$

where

$$
\begin{gathered}
\hat{S F}=S F \cdot \frac{T P P}{T P P^{*}} \\
\hat{D R}=1-S R-\hat{S F} .
\end{gathered}
$$

As detrital silica returns to solution primarily via dissolution rather than active remineralization, it is assumed that oxygen depletion has a negligible effect and the silicic acid equations are unchanged.

\section{A5. Increased Vertical Resolution}

[121] In this extension to the model, the top layer represents the euphotic zone, and is the only layer in which the phytoplankton are represented (their equations remain unchanged). The middle layer represents the extent of seasonal mixing of the surface ocean, and contains both nutrients. The deep layer remains unchanged. The resulting equations for silicic acid are

$$
\begin{aligned}
\frac{d S_{s}}{d t}= & -\left[\mu_{D} \cdot \min \left(\frac{P_{s}}{P_{s}+K_{p}}, \frac{S_{s}}{S_{s}+K_{s}}\right) \cdot D \cdot R_{\text {org }}\right] \\
& +\left[S R_{s} \cdot M \cdot D \cdot R_{\text {org }}\right]+\left[K_{2} \cdot \frac{S_{m}-S_{s}}{S D}\right]+\left[\frac{R S+A S}{S D}\right], \\
\frac{d S_{m}}{d t}= & +\left[M R_{s} \cdot M \cdot D \cdot R_{\text {org }} \cdot \frac{S D}{M D}\right]-\left[K_{2} \cdot \frac{S_{m}-S_{s}}{M D}\right] \\
& +\left[K \cdot \frac{S_{d}-S_{m}}{M D}\right],
\end{aligned}
$$

$$
\frac{d S_{d}}{d t}=+\left[D R_{s} \cdot M \cdot D \cdot R_{\text {org }} \cdot \frac{S D}{D D}\right]-\left[K \cdot \frac{S_{d}-S_{m}}{D D}\right]+\left[\frac{H S+W S}{D D}\right] .
$$

The equations for phosphate are modified in the same fashion and so are not shown.

\section{A6. Multiplicative Nutrient Limitation}

[122] An alternative approach to modeling multiple nutrient limitations is to simply multiply all of the MichaelisMenten terms together [O'Neill et al., 1989].

$$
\frac{d D}{d t}=+\left[\mu_{D} \cdot \frac{P_{s}}{P_{s}+K_{p}} \cdot \frac{S_{s}}{S_{s}+K_{s}} \cdot D\right]-[M \cdot D] .
$$

\section{A7. As Above, Increased Diatom Growth}

[123] However, since each of these terms is less than 1, successive multiplication can make two moderately limiting nutrients strongly limit phytoplankton growth. Consequently, sensitivity test 7 increases the value of $\mu_{D}$ to compensate.

\section{A8. Dissolved Organic Phosphate}

[124] Semi-labile DOP is added to the model and represented in both the surface and deep boxes. It is produced through phytoplankton mortality and decays back to phosphate on an annual timescale.

$$
\begin{aligned}
\frac{d D O P_{s}}{d t}= & +[\sigma \cdot M \cdot O]+[\sigma \cdot M \cdot D]-\left[\lambda \cdot D O P_{s}\right] \\
& +\left[K \cdot \frac{D O P_{d}-D O P_{s}}{S D}\right],
\end{aligned}
$$




$$
\begin{aligned}
& \frac{d D O P_{d}}{d t}=-\left[\lambda \cdot D O P_{d}\right]-\left[K \cdot \frac{D O P_{d}-D O P_{s}}{D D}\right], \\
\frac{d P_{s}}{d t}= & \ldots+[S R \cdot(1-\sigma) \cdot M \cdot O]+\left[S R_{p} \cdot(1-\sigma) \cdot M \cdot D\right] \\
& +\left[\lambda \cdot D O P_{s}\right], \\
\frac{d P_{d}}{d t}= & \ldots+[S R \cdot(1-\sigma) \cdot M \cdot O]+\left[S R_{p} \cdot(1-\sigma) \cdot M \cdot D\right] \\
& +\left[\lambda \cdot D O P_{s}\right] .
\end{aligned}
$$

\section{A9. Adding Explicit Zooplankton}

[125] The equations for the zooplankton model are

$$
\begin{aligned}
& \frac{d O}{d t}=+\left[\mu_{O} \cdot \frac{P_{s}}{P_{s}+K_{p}} \cdot O\right]-\left[G \cdot \frac{F}{F+K_{f}} \cdot O \cdot Z\right], \\
& \frac{d D}{d t}=+\left[\mu_{D} \cdot \min \left(\frac{P_{s}}{P_{s}+K_{p}}, \frac{S_{s}}{S_{s}+K_{s}}\right) \cdot D\right] \\
& -\left[G \cdot \frac{F}{F+K_{f}} \cdot D \cdot Z\right] \text {, } \\
& \frac{d Z}{d t}=+\left[G \cdot \frac{F}{F+K_{f}} \cdot F \cdot Z\right]-\left[\hat{M} \cdot Z^{2}\right] \\
& \frac{d P_{s}}{d t}=\ldots+\left[S R \cdot \hat{M} \cdot Z^{2}\right] \ldots, \\
& \frac{d S_{s}}{d t}=\ldots+\left[S R_{s} \cdot G \cdot \frac{F}{F+K_{f}} \cdot D \cdot Z \cdot R_{\text {org }}\right] \ldots, \\
& \frac{d P_{d}}{d t}=+\left[D R \cdot \hat{M} \cdot Z^{2} \cdot \frac{S D}{D D}\right] \ldots, \\
& \frac{d S_{d}}{d t}=+\left[D R_{s} \cdot G \cdot \frac{F}{F+K_{f}} \cdot D \cdot Z \cdot R_{o r g} \cdot \frac{S D}{D D}\right] \ldots,
\end{aligned}
$$

where

$$
F=[O+D]
$$

Essentially, phytoplankton losses are now no longer directly remineralized, but pass first through the zooplankton compartment. In the case of phosphate, this is assimilated by the zooplankton and released via their own loss processes. Since silicon is not utilized by the majority of zooplankton, it is immediately egested by the model zooplankton. As is clear from the equations, remineralization proceeds in a similar manner to the base model.
Zooplankton mortality is modeled by a standard quadratic function [Edwards and Yool, 2000].

\section{A10. Implicit Iron Limitation}

[126] A major hurdle in adding iron to models is that it exists in seawater in several forms (oxides, hydroxides, organic complexes), which vary in their solubility and thus their utility to phytoplankton. Fung et al. [2000] give a brief overview of some of the complexities of iron biogeochemistry. Consequently, iron's behavior in the ocean is difficult to model, and in this attempt it is modeled on an implicit basis. Both phytoplankton groups are assumed to require iron equally and their growth equations are primarily modified as follows:

$$
\begin{gathered}
\frac{d O}{d t}=+\left[\mu_{O} \cdot \min \left(\frac{P_{s}}{P_{s}+K_{p}}, F e_{\text {lim }}\right)\right]-\left[\hat{M} \cdot O^{2}\right] \\
\frac{d D}{d t}=+\left[\mu_{D} \cdot \min \left(\frac{P_{s}}{P_{s}+K_{p}}, \frac{S_{s}}{S_{s}+K_{p}}, F e_{\text {lim }}\right)\right]-\left[\hat{M} \cdot D^{2}\right] .
\end{gathered}
$$

Both equations now include an extra limitation term, $F e_{\text {lim }}$. Like the terms for silicic acid and phosphate, this ranges between 0 (total limitation) and 1 (no limitation). As iron is only handled implicitly here, $F e_{\text {lim }}$ is given a constant value. This potentially causes a problem with the phytoplankton mortality terms. As these are linear (i.e., biomass independent), at equilibrium the nutrient-limited growth rate perfectly balances this fixed mortality rate. Thus the nutrient limitation terms can never fall below a certain value $(0.769$ for the diatoms; 0.800 for the other algae). Introducing a new limitation term, and one which needs to be more limiting than the existing ones for it to limit phytoplankton growth, would drag phytoplankton growth below mortality and lead to extinction. However, use of a nonlinear mortality rate resolves this problem by permitting phytoplankton growth rates to range freely. In the first instance a quadratic mortality term is used, with the parameter $\hat{M}$ as a modified form of $M$. Its value $\left.\left(50 \mathrm{yr}^{-1}(\mu \mathrm{mol} \mathrm{m})^{-3}\right)^{-1}\right)$ has been chosen so that the model equilibrium is approximately the same as that of the base model.

[127] Aside from these changes, the model equations remain the same. As only certain regions of the world ocean are iron limited, the two-box structure of the model is divided into a four-box structure with two horizontal regions. These regions nominally represent the iron limited Southern Ocean (20\% by volume) and the iron replete remainder of the ocean (though other regions of the ocean are also believed to be limited by iron) [Martin and Fitzwater, 1988]. The two regions contain the same state variables, and as they are not isolated a small amount of mixing is parameterized between them. For iron-limited simulations, the values of $\mathrm{Fe}_{\text {lim }}$ for each region can be specified separately.

\section{A11. Semi-Explicit Iron Limitation}

[128] Building on the framework described above, this model includes iron limitation more explicitly by modeling 
iron concentration and processes which affect it in the Southern Ocean. In this region the phytoplankton equations are modified to include a Michaelis-Menten term for iron,

$$
\begin{gathered}
\frac{d O}{d t}=+\left[\mu_{O} \cdot \min \left(\frac{P_{s}}{P_{s}+K_{p}}, \frac{F_{s}}{F_{s}+K_{f, o}}\right)\right]-\left[\hat{M} \cdot O^{2}\right] \quad(\mathrm{A} 26) \\
\frac{d D}{d t}=+\left[\mu_{D} \cdot \min \left(\frac{P_{s}}{P_{s}+K_{p}}, \frac{S_{s}}{S_{s}+K_{p}}, \frac{F_{s}}{F_{s}+K_{f, d}}\right)\right]-\left[\hat{M} \cdot D^{2}\right] .
\end{gathered}
$$

[129] The remaining model equations are essentially unchanged, with minor modifications to accommodate the new nutrient limitation factor. However, a further differential equation is added to model iron concentrations in the surface Southern Ocean,

$$
\begin{aligned}
\frac{d F_{s}}{d t}= & -\underbrace{\left[\mu_{O} \cdot \min \left(\frac{P_{s}}{P_{s}+K_{p}}, \frac{F_{s}}{F_{s}+K_{f, o}}\right) \cdot O \cdot R_{f: p}\right]}_{\text {O uptake }} \\
& +\underbrace{\left[\hat{M} \cdot O^{2} \cdot R_{f: p}\right]}_{\text {O surface remin }} \\
& -\underbrace{\left[\mu_{D} \cdot \min \left(\frac{P_{s}}{P_{s}+K_{p}}, \frac{S_{S}}{S_{s}+K_{p}}, \frac{F_{s}}{F_{s}+K_{f, d}}\right) \cdot D \cdot R_{f: p}\right]}_{\text {D uptake }} \\
& +\underbrace{\left[\hat{M} \cdot D^{2} \cdot R_{f: p}\right]}_{\text {D surface remin }} \\
& +\underbrace{\left[\frac{\left(F_{\text {sol }} \cdot A F\right)+U F}{S D}\right]}_{\text {aeolian and upwelling input }}-\underbrace{\left[F_{\text {scav }} \cdot F_{s}\right]}_{\text {Fe scavenging }} .
\end{aligned}
$$

[130] The values for the new model parameters introduced here are taken from Fung et al. [2000] (AF and UF), Jickells and Spokes [2001] $\left(F_{\text {sol }}\right)$, Ridgwell [2001] $\left(K_{f, o}\right.$ and $\left.K_{f, d}\right)$, and Moore et al. [2002] ( $R_{f: p}$ and $\left.F_{\text {scav }}\right)$. The new equation for iron models its limiting effects on phytoplankton in the Southern Ocean, its input via aeolian dust deposition and upwelling, and its loss via sinking organic material and chemical/particle scavenging from the water column. Even with these extra processes the still model considerably simplifies biogeochemical cycling of iron. However, the intention here is to incorporate the most important processes and to permit separate specification of iron uptake kinetics between the two phytoplankton groups [Ridgwell, 2001; Moore et al., 2002].

\section{A12. Diatom Competitive Advantage}

[131] The modified phytoplankton equations become

$$
\begin{gathered}
\frac{d O}{d t}=+\left[\mu \cdot \frac{P_{s}}{P_{s}+K_{p}} \cdot O\right]-\left[M_{O} \cdot O\right] \\
\frac{d D}{d t}=+\left[\mu \cdot \min \left(\frac{P_{s}}{P_{s}+K_{p}}, \frac{S_{s}}{S_{s}+K_{s}}\right) \cdot D\right]-\left[M_{D} \cdot D\right] .
\end{gathered}
$$

where $\mu$ is now the common maximum growth rate, and the mortality rates for the other algae and diatoms are, respectively, $M_{O}$ and $M_{D}$. The other model equations are similarly changed but for brevity are not reproduced here.

\section{A13. Other Algae are Picophytoplankton}

[132] This model builds on the earlier zooplankton model to alter the ecological structure to a size-based two-phytoplankton, two-zooplankton form. The other algae are assumed to be picophytoplankton, and are grazed down by fast growing microzooplankton $\left(Z_{\mu}\right)$. The diatoms are assumed to be larger phytoplankton, and are grazed separately by mesozooplankton $\left(Z_{m}\right)$.

$$
\begin{gathered}
\frac{d O}{d t}=+\left[\mu_{O} \cdot \frac{P_{s}}{P_{s}+\hat{K}_{p}} \cdot O\right]-\left[G_{\mu} \cdot \frac{O}{O+K_{\mu}} \cdot O \cdot Z_{\mu}\right], \\
\frac{d D}{d t}=+\left[\mu_{D} \cdot \min \left(\frac{P_{s}}{P_{s}+K_{p}}, \frac{S_{s}}{S_{s}+K_{s}}\right) \cdot D\right] \\
-\left[G_{m} \cdot \frac{D}{D+K_{m}} \cdot D \cdot Z_{m}\right], \\
\frac{d Z_{\mu}}{d t}=+\left[G_{\mu} \cdot \frac{O}{O+K_{\mu}} \cdot O \cdot Z_{\mu}\right]-\left[\hat{M}_{\mu} \cdot Z_{\mu}^{2}\right], \\
\frac{d Z_{m}}{d t}=+\left[G_{m} \cdot \frac{D}{D+K_{m}} \cdot D \cdot Z_{m}\right]-\left[\hat{M}_{m} \cdot Z_{m}^{2}\right] .
\end{gathered}
$$

[133] As well as having a greater maximum growth rate $(+50 \%)$, the other algae also have a lower $(-50 \%)$ phosphate uptake half-saturation constant $\left(\hat{K}_{p}\right)$. Microzooplankton are assumed to have both a higher $(+50 \%)$ maximum growth rate $\left(G_{\mu}\right)$ than mesozooplankton, and a lower $(-50 \%)$ grazing half-saturation constant $\left(K_{\mu}\right)$ to represent a faster grazing response to their prey. The model remains otherwise the same as the zooplankton model described earlier.

\section{A14. Deeper Diatom Phosphate Remineralization}

[134] This modification to the model simply involves changes to the diatom phosphate remineralization parameters, $S R_{p}$ and $D R_{p}$. The diatom phosphate sedimentation parameter, $S F$, remains unchanged. Section 5 examines this situation more closely.

\section{A15. Variable Silica Sedimentation Fraction}

[135] The primary modification to the model centers on the dissolution profile for biogenic silica. The modified dissolution parameters appear in the model's nutrient equations which, because of the simplicity of the change, are not reproduced here.

$$
\hat{S R_{s}}=0.50
$$

$$
\hat{S F}_{S}=0.028556 \cdot \exp \left(0.2388 \cdot\left[\frac{D \cdot M \cdot \hat{R}_{\text {org }}}{D^{*} \cdot M \cdot R_{\text {org }}} \cdot 8.2785\right]\right),
$$

$$
\hat{D R_{S}}=1-\hat{S R}_{S}-\hat{S F}_{S}
$$


[136] The surface dissolution fraction, $\hat{S R}_{s}$, remains unchanged, while the sedimentation fraction, $\hat{S F}_{s}$, incorporates Ragueneau et al.'s [2000] equation. Since this equation can return preservation efficiencies greater than $100 \%$, the implementation in the model includes a minimizing function to prevent errors. The deep dissolution fraction, $\hat{D R} R_{s}$, makes up the remaining fraction of dissolution.

\section{A16. Diatom Frustule Thinning}

[137] When under silicic acid stress, diatoms are known to lose their setae (spines) and to thin their frustules [Flynn and Martin-Jézéquel, 2000]. This allows them to reduce their Si:P ratio below that which they adopt in optimal growth conditions, but with the advantage that they can complete a division cycle on a lower silicon budget. This process is not included in the base model, where diatoms are constrained such that $\hat{R}_{\text {org }}$ cannot be less than $R_{\text {org }}$. In this modification, $\hat{R}_{\text {org }}$ is redefined such that it can assume values above and below $R_{\text {org }}$ dependent upon the prevailing nutrient conditions.

$$
\hat{R}_{\text {org }}=R_{\text {org }} \cdot\left[\frac{S_{s}}{S_{s}+K_{s}}\right] \cdot\left[\frac{P_{s}}{P_{s}+K_{p}}\right]^{-1}
$$

[138] However, as described in the main text, diatoms are known to be less dominant whenever they are under silicic acid stress. Presumably this occurs because of poorly known "trade-offs" between frustule thickness and ecological success. This is underscored by recent work examining the mechanical strength of frustules and its potential role in defense from grazers [Hamm et al., 2003]. To represent this loss in ecological performance, diatom mortality rate, $M_{D}$, is made a function of $\hat{R}_{\text {org }}$.

$$
M_{D}=M \cdot\left[\max \left(\frac{R_{\text {org }}}{\hat{R}_{\text {org }}}, 1\right)\right] .
$$

The model's differential equations are appropriately modified to include these changes.

[139] Acknowledgments. We thank T. Anderson, M. Baird, C. Binns, A. Edwards, M. Fasham, K. Flynn, J. Greenwood, P. Tréguer, and V. Truesdale for many helpful suggestions during the development of this model. The authors are also grateful to two anonymous reviewers whose invaluable comments and advice greatly improved the final form of this manuscript. A. Y. is funded by a U. K. Natural Environment Research Council grant (GR3/12051). T. T. is supported by a U. K. Natural Environment Research Council fellowship (GT5/98/15/MSTB).

\section{References}

Antoine, D., J.-M. André, and A. Morel, Oceanic primary production: 2. Estimation at a global scale from satellite (Coastal Zone Colour Scanner) chlorophyll, Global Biogeochem. Cycles, 10, 57-69, 1996.

Armstrong, R. A., C. Lee, J. I. Hedges, S. Honjo, and S. G. Wakeham, A new, mechanistic model for organic carbon fluxes in the ocean: Based on the quantitative association of POC with ballast minerals, Deep Sea Res., Part II, 49, 219-236, 2002.

Banse, K., Grazing, temporal changes of phytoplankton concentrations, and the microbial loop in the open sea, in Primary Productivity and Biogeochemical Cycles in the Sea, edited by P. G. Falkowski and A. D. Woodhead, pp. 409-440, Plenum, New York, 1992.

Blain, S., A. Leynaert, P. Tréguer, M. C. Chretiennot-Dinet, and M. Rodier, Biomass, growth rates and limitation of equatorial Pacific diatoms, Deep Sea Res., Part I, 44, 1255-1275, 1997.
Broecker, W. S., A kinetic model for the composition of sea water, Quat. Res., 1, 188-207, 1971.

Broecker, W. S., and T.-H. Peng, Tracers in the Sea, Eldigio, New York, 1982. Brzezinski, M. A., T. A. Villareal, and F. Lipschultz, Silica production and the contribution of diatoms to new and primary production in the central North Pacific, Mar. Ecol. Prog. Ser., 167, 89-104, 1998.

Clark, D. R., K. J. Flynn, and N. J. P. Owens, The large capacity for dark nitrate-assimilation in diatoms may overcome nitrate limitation of growth, New Phytol., 155, 101-108, 2002.

Conkright, M., S. Levitus, and T. P. Boyer, World Ocean Atlas 1994, vol. 1, Nutrients, NOAA Atlas NESDIS 1, 162 pp., Natl. Oceanic and Atmos. Admin., Silver Spring, Md., 1994.

Conley, D. J., C. L. Schelske, and E. F. Stoermer, Modification of the biogeochemical cycle of silica with eutrophication, Mar. Ecol. Prog. Ser., 101, 179-192, 1993.

Dugdale, R. C., and F. P. Wilkerson, Silicate regulation of new production in the equatorial Pacific upwelling, Nature, 391, 270-273, 1998.

Edwards, A. M., and A. Yool, The role of higher predation in plankton population models, J. Plankton Res., 22, 1085-1112, 2000.

Egge, J. K., Are diatoms poor competitors at low phosphate concentrations?, J. Mar. Syst., 16, 191-198, 1998.

Egge, J. K., and D. L. Aksnes, Silicate as regulating nutrient in phytoplankton competition, Mar. Ecol. Prog. Ser., 83, 281-289, 1992.

Engel, A., S. Goldthwait, U. Passow, and A. Alldredge, Temporal decoupling of carbon and nitrogen dynamics in a mesocosm diatom bloom, Limnol. Oceanogr., 47, 753-761, 2002.

Fasham, M. J. R., Modelling the marine biota, in The Global Carbon Cycle, edited by M. Heimann, pp. 457-504, Springer-Verlag, New York, 1993.

Fasham, M. J. R., H. W. Ducklow, and S. M. McKelvie, A nitrogen-based model of plankton dynamics in the oceanic mixed layer, J. Mar. Res., 48, $591-639,1990$

Flynn, K. J., and V. Martin-Jézéquel, Modelling Si-N-limited growth of diatoms, J. Plankton Res., 22, 447-472, 2000.

Frangoulis, C., S. Belkhiria, A. Goffart, and J. H. Hecq, Dynamics of copepod faecal pellets in relation to a Phaeocystis dominated phytoplankton bloom: Characteristics, production and flux, J. Plankton Res., 23, $75-88,2001$.

Fryxell, G. A., and W. I. Miller III, Chain-forming diatoms: Three araphid species, Bacillaria, 1, 113-136, 1978.

Fung, I. Y., S. K. Meyn, I. Tegen, S. C. Doney, J. G. John, and J. K. B. Bishop, Iron supply and demand in the upper ocean, Global Biogeochem. Cycles, 14, 281-295, 2000.

Furnas, M. J., In situ growth rates of marine phytoplankton: Approaches to measurement, community and species growth rates, J. Plankton Res., 12, 1117-1151, 1990.

Hamm, C. E., R. Merkel, O. Springer, P. Jurkojc, C. Maler, K. Prechtel, and V. Smetacek, Architecture and material properties of diatom shells provide effective mechanical protection, Nature, 421, 841-843, 2003.

Humborg, C., V. Ittekkot, A. Cociasu, and B. Von Bodungen, Effect of Danube River dam on Black Sea biogeochemistry and ecosystem structure, Nature, 386, 385-388, 1997.

Hutchins, D. A., and K. W. Bruland, Iron-limited diatom growth and Si:N uptake ratios in a coastal upwelling regime, Nature, 393, 561-564, 1998.

Ingall, E. D., and P. Van Capellen, Relation between sedimentation rate and burial of organic phosphorus and organic carbon in marine sediments, Geochim. Cosmochim. Acta, 54, 373-386, 1990.

Jickells, T. D., and L. J. Spokes, Atmospheric iron inputs to the oceans, in The Biogeochemistry of Iron in Seawater, edited by D. Turner and K. Hunter, pp. 85-121, John Wiley, New York, 2001.

Kamatani, A., Dissolution rates of silica from diatoms decomposing at various temperatures, Mar. Biol., 68, 91-96, 1982.

Kidder, D. L., and D. H. Erwin, Secular distribution of biogenic silica through the Phanerozoic: Comparison of silica-replaced fossils and bedded cherts at the series level, J. Geol., 109, 509-522, 2001.

Klaas, C., and D. E. Archer, Association of sinking organic matter with various types of mineral ballast in the deep sea: Implications for the rain ratio, Global Biogeochem. Cycles, 16(4), 1116, doi:10.1029/ 2001GB001765, 2002.

Littler, M. M., D. S. Littler, S. M. Blair, and J. N. Norris, Deepest known plant life discovered on an uncharted seamount, Science, 227, 57-59, 1985.

Longhurst, A., S. Sathyendranath, T. Platt, and C. Caverhill, An estimate of global primary production in the ocean from satellite radiometer data, J. Plankton Res., 17, 1245-1271, 1995.

Louanchi, F., and R. G. Najjar, A global monthly climatology of phosphate, nitrate, and silicate in the upper ocean: Spring-summer export production and shallow remineralization, Global Biogeochem. Cycles, 14, 957-977, 2000 . 
Mackenzie, F. T., L. M. Ver, C. Sabine, M. Lane, and A. Lerman, C, N, P and $\mathrm{S}$ global biogeochemical cycles and modelling of global change, in Interactions of C, N, P and S Biogeochemical Cycles and Global Change, NATO ASI Ser., vol. 14, edited by R. Wollast, F. T. Mackenzie, and L. Chou, pp. 1-61, Springer-Verlag, New York, 1993.

Mann, D. G., The species concept in diatoms, Phycologia, 38, 437-495, 1999.

Martin, J. H., and S. E. Fitzwater, Iron-deficiency limits phytoplankton growth in the northeast Pacific subarctic, Nature, 331, 341-343, 1988.

Martin, J. H., R. M. Gordon, and S. E. Fitzwater, Iron in Antarctic waters, Nature, 345, 156-158, 1990.

Martin-Jézéquel, V., M. Hildebrand, and M. A. Brzezinski, Silicon metabolism in diatoms: Implications for growth, J. Phycol., 36, 821-840, 2000.

McGowran, B., Silica burp in the Eocene ocean, Geology, 17, 857-860, 1989.

Milligan, A. J., and F. M. M. Morel, A proton buffering role for silica in diatoms, Science, 297, 1848-1850, 2002.

Moore, J. K., S. C. Doney, J. K. Kleypas, D. M. Glover, and I. Y. Fung, An intermediate complexity marine ecosystem model for the global domain, Deep Sea Res., Part II, 49, 403-462, 2002.

Nelson, D. M., and M. A. Brzezinski, Diatom growth and productivity in an oligotrophic mid-ocean gyre: A 3-year record from the Sargasso Sea near Bermuda, Limnol. Oceanogr., 42, 473-486, 1997.

O'Neill, R. V., D. L. Angelis, J. J. Pastor, B. J. Jackson, and W. M. Post, Multiple nutrient limitation in ecological models, Ecol. Modell., 46, $147-163,1989$.

Palmer, J. R., and I. J. Totterdell, Production and export in a global ocean ecosystem model, Deep Sea Res., Part I, 48, 1169-1198, 2001.

Pondaven, P., C. Fravalo, D. Ruiz-Pino, P. Tréguer, B. Quéguiner, and C. Jeandel, Modelling the silica pump in the Permanently Open Ocean Zone of the Southern Ocean, J. Mar. Syst., 17, 587-619, 1998.

Ragueneau, O., et al., A review of the Si cycle in the modern ocean: Recent progress and missing gaps in the application of biogenic opal as a paleoproductivity proxy, Global Planet Change, 26, 317-365, 2000.
Raven, J. A., The transport and function of silicon in plants, Biol. Rev., 58 , 179-207, 1983

Ridgwell, A. J., Glacial-interglacial perturbations in the global carbon cycle, Ph.D. thesis, Univ. of East Anglia, Norwich, U. K., 2001.

Ruttenberg, K. C., Reassessment of the oceanic residence time of phosphorus, Chem. Geol., 107, 405-409, 1993.

Schlesinger, W. H., Biogeochemistry: An Analysis of Global Change, Academic, San Diego, Calif., 1991.

Siever, R., Silica in the oceans: Biological-geological interplay, in Scientists On Gaia, edited by S. H. Schneider and P. J. Boston, pp. 287-295, MIT Press, Cambridge, Mass., 1991.

Smetacek, V. S., Role of sinking in diatom life-history cycles: Ecological, evolutionary and geological significance, Mar. Biol., 84, 239-251, 1985.

Takeda, S., Influence of iron availability on nutrient consumption ratio of diatoms in oceanic waters, Nature, 393, 774-777, 1998.

Thibault, D., S. Roy, C. S. Wong, and J. K. Bishop, The downward flux of biogenic material in the NE subarctic Pacific: Importance of algal sinking and mesozooplankton herbivory, Deep Sea Res., Part II, 46, 2669-2697, 1999.

Tréguer, P., D. M. Nelson, A. J. Van Bennekom, D. J. DeMaster, A. Leynaert, and B. Quéguiner, The silica balance in the world ocean: A reestimate, Science, 268, 375-379, 1995.

Tyrrell, T., The relative influences of nitrogen and phosphorus on oceanic primary production, Nature, 400, 525-531, 1999.

Villareal, T. A., L. Joseph, M. A. Brzezinski, R. F. Shipe, F. Lipschultz, and M. A. Altabet, Biological and chemical characteristics of the giant diatom Ethmodiscus (Bacillariophyceae) in the central North Pacific gyre, J. Phycol., 35, 896-902, 1999.

T. Tyrell and A. Yool, Southampton Oceanography Centre, European Way, Southampton SO14 3ZH, UK. (axy@soc.soton.ac.uk) 